\title{
A Comissão Intergestores Bipartite a CIB do Rio de Janeiro
}

LUCIANA DIAS DE LIMA'

Este artigo apresenta uma investigação exploratória acerca do funcionamento das Comissões Intergestores Bipartite (CIB), enquanto novos centros de decisão na política de saúde. Através da análise de um caso concreto - a CIB do estado do Rio de Janeiro (CIB/RJ) - procurou-se refletir de que forma variáveis internas à política de saúde podem contribuir para a construção do pacto federativo no âmbito da saúde e para implementação do modelo de sistema de saúde presente no SUS. As CIB têm desempenhado papel fundamental na operacionalização das diretrizes nacionais e na descentralização do sistema de saúde. Observou-se que a execução da política, através de instâncias colegiadas de gestão, permite a construção da parceria estado e municípios e a consolidação de uma prática de negociação entre os gestores locais da política - mais equilibrada, democrática e participativa. No entanto, o estudo no RJ sugere que as CIB ainda necessitam avançar no processo de discussão e formulação coletiva para o enfrentamento dos problemas locoregionais, visando à estruturação do sistema intermunicipal e estadual de saúde.

Palavras-chave: Comissão Intergestores Bipartite; descentralização das políticas de saúde; relações intergovernamentais; sistema de saúde. 


\section{Introdução}

Este artigo é fruto de dissertação de mestrado (Lima, 1999), a partir de uma investigação exploratória acerca do funcionamento de novos centros de decisão - as Comissões Intergestores Bipartite (CIB) - na política de saúde. Estas instâncias, de formação recente, foram criadas a partir de determinação da Norma Operacional Básica do Sistema Único de Saúde 01 de 1993 (NOB SUS 01/93) e constituem centros de gestão colegiados, paritários e permanentes, principalmente para operacionalização do processo de descentralização em curso na política de saúde.

Analisa-se, através do caso da CIB do estado do Rio de Janeiro (CIB/ $\mathrm{RJ}$ ), de que forma variáveis internas à política de saúde, podem contribuir para a construção do pacto federativo no âmbito da saúde e para implementação do SUS: Quais os principais assuntos abordados na CIB? Quais suas principais deliberações? Como tem sido a atuação da representação estadual e municipal na CIB? E o processo decisório? Quais os principais conflitos evidenciados? De que forma as determinações federais da política de saúde, principalmente no que diz respeito às Normas Operacionais Básicas do SUS, têm influenciado o funcionamento da CIB? De que forma outros elementos do sistema estadual influenciam a negociação na CIB? A CIB pode atuar no sentido de resgatar as funções específicas da instância estadual frente ao tipo de relações federativas existentes e ao direcionamento municipalista da política de saúde? Em que medida a CIB pode contribuir para a integração, hierarquização e regionalização do sistema de saúde?

A opção por um estudo de caso está relacionada à própria complexidade do tema das relações intergovernamentais no campo das políticas públicas e, especificamente, no campo das políticas de saúde. Sabe-se que estas relações estão condicionadas à uma série de variáveis - econômicas, políticas, culturais e históricas - próprias das diversas localidades, que ajudam a moldá-las e que a particularizam frente ao restante da federação. Além disso, alguns fatores geradores de conflitos na área assistencial, como aqueles relacionados às capacidades de organizaçăo e gestão das redes de serviços de saúde existentes nas diferentes esferas de governo, podem ser mais claramente identificados.

Particularmente, o estado do Rio de Janeiro constitui experiência ímpar para a formação do sistema estadual de saúde, já que o município do Rio de Janeiro possui a maior rede de serviços públicos federais existentes no Brasil e, por isso mesmo, necessitar de maior articulação entre as três 
esferas de governo para composição e organização do sistema de saúde loco-regional.

No estudo das relações intergovernamentais na $\mathrm{CIB} / \mathrm{RJ}$, identificou-se os períodos de inflexão ou mudança na relação entre estado e municípios sobservadas no funcionamento da $\mathrm{CIB} / \mathrm{RJ}$ desde sua implantação até o final de 1998.

Foram estabelecidas então quatro fases de funcionamento da CIB/RJ.

1. 1993 a 1994 - O processo de implantação da CIB no RJ.

2. Janeiro de 1995 a agosto de 1996 - A CIB como instrumento de aproximação entre estado e municípios.

3. Setembro de 1996 a abril de 1997 - A fase de transição no relacionamento entre estado e municípios.

4. Maio de 1997 a dezembro de 1998 - A fase de conflito aberto entre estado e municípios: período da gestão competitiva.

A periodização da CIB/RJ aqui apresentada reflete diferentes modalidades de interação entre as instâncias subnacionais de governo que nela atuam para a organização do sistema de saúde estadual - mais cooperativas/ integradoras ou mais competitivas/desintegradoras -, obtidas através do relato dos entrevistados na pesquisa e da análise das atas das reuniões realizadas.

No entanto, diferentes modalidades de interação com graus variáveis de cooperação/competição, integração/desintegração, puderam ser observadas, mais claramente ou não, nos diferentes momentos do funcionamento da $\mathrm{CIB} / \mathrm{RJ}$, influenciadas por fatores de ordem diversa: postura adotada pela Secretaria de Estado de Saúde e COSEMS/RJ; forma de organização e funcionamento interno da CIB/RJ; conjuntura política; variações nas normatizações federais para a implementação do SUS; conteúdos dos diferentes assuntos abordados nas reuniões; participação e intermediação da representação federal, entre outros. Desta forma, os períodos foram delimitados com base na modalidade de relacionamento entre as esferas de governo mais facilmente observável e considerada preponderante nas fases estudadas.

Cabe ainda destacar que, esta periodização, enquanto primeiro produto das análises efetuadas sobre o funcionamento da CIB/RJ, foi também utilizada como um recurso para melhor compreensão da influência que os diferentes arranjos no relacionamento entre as instâncias subnacionais podem ter sobre o sistema de saúde estadual. 


\section{O Processo de Implantação da CIB no RJ (1993 a 1994)}

\subsection{A Fase Inicial: a Importância do COSEMS/RJ}

A CIB/RJ foi criada oficialmente em 12 de julho de 1993, através da Resolução n⿳0 $855 /$ SES/RJ. No entanto, as reuniões da Comissão só começam a acontecer de forma regular e periódica (geralmente mensal), a partir do primeiro semestre de 1994. Para o início das reuniões da CIB no RJ o COSEMS/RJ ${ }^{2}$ teve uma atuação decisiva.

Centrado na figura de seu presidente, o Secretário Municipal de Saúde de Niterói, Dr. Gilson Cantarino O'Dwyer, o COSEMS/RJ inicia e lidera, a partir de 1993, o processo de negociação política para implantação da CIB no RJ. A principal estratégia utilizada pelo COSEMS/RJ foi a convocação de todos os secretários municipais de saúde, através das suas Vice-Presidências Regionais ${ }^{3}$, a denunciarem ao Dr. Gilson Carvalho, Diretor do Departamento do SUS da SAS/MS, as resistências apresentadas pela SES/RJ à implantação da CIB/RJ. Entre estas, o atraso da nomeação dos membros da CIB/RJ e as dificuldades para a marcação das reuniões em que se daria início à discussão sobre os processos de habilitação e definição dos tetos financeiros municipais, segundo as determinações da NOB SUS 01/93.

As denúncias culminaram com a intervenção do MS, através da delegação de um representante para auxiliar o processo de organização e o início das reuniões ${ }^{4}$ e com a ameaça de suspensão do repasse dos recursos federais do SUS para o estado. Esta última medida, no entanto, não foi levada à cabo e o repasse acabou se consumando no mês de competência previsto.

As dificuldades de relacionamento entre a SES/RJ e a capital também radicalizaram os conflitos entre estado e municípios no processo de implantação da CIB/RJ. Uma expressão disto foi tentativa de obstrução por parte da SES/RJ da participação do suplente do Dr. Ronaldo Luiz Gazolla ${ }^{5}$, Secretário Municipal de Saúde do RJ, nas reuniões da CIB/RJ. A SES/RJ tentou suspender a indicação do Dr. Gazolla, solicitando a nomeação de um outro Secretário Municipal de Saúde em lugar do representante da capital. Esta situação só foi sanada com a intervenção do representante do MS.

Mesmo com as dificuldades acima apontadas, após a implantação da $\mathrm{CIB} / \mathrm{RJ}$, deu-se início ao processo de discussão e negociação fundamentais para as deliberações que se seguiram posteriormente. 


\subsection{O Contexto de Implantação}

A criação da CIB no estado do Rio de Janeiro se deu em uma conjuntura de intensos conflitos políticos entre estado e municípios. Esses conflitos possuem: 1) determinações mais amplas, relacionadas a forma como estavam estruturados os relacionamentos entre as instâncias federal, estadual e municipais na política de saúde e; 2) determinações específicas, relacionadas à forma da atuação da secretaria estadual e municipais de saúde na época.

O período que marca o contexto de implantação da CIB/RJ (1991 a 1994) é caracterizado por importantes mudanças nas políticas de saúde das três esferas de governo. No plano federal, o período caracteriza-se por alterações nos mecanismos de repasse financeiro dos recursos federais para a área da saúde. A modalidade de "pós-pagamento" por produção, adotada para o custeio da assistência ambulatorial e hospitalar e o mecanismo convenial estabelecido entre o nível federal e o municipal sem a participação estadual, a partir de determinações das portarias do MS e da NOB SUS 01/ 91 e 01/92, tiveram impactos negativos na relação estado-municípios, diminuindo o poder de influência dos estados na realocação dos recursos da saúde (característica marcante do período SUDS - 1987 a 1989), e induzindo a uma maior desintegração e descoordenação dos sistemas municipais de saúde.

No plano estadual, o período 1991 a 1994 destaca-se por uma série de retrocessos à descentralização do sistema de saúde observada na gestão anterior, com fortes resistências às transferências de competências aos municípios e denúncias quanto a desvios financeiros e privilégios políticopartidários, no que se refere aos investimentos e ao repasse de recursos, seja para o setor privado, seja para alguns municípios ${ }^{6}$.

As mudanças efetivadas no período de 1987 a 1990 - municipalização adotada com o repasse de unidades estaduais e federais para os municípios; transferência de responsabilidades de contratação, controle e avaliação dos serviços de terceiros (incluindo privados e filantrópicos); extinção das Coordenadorias Regionais de Saúde da SES/RJ ${ }^{7}$; assessoramento e formação de novos técnicos nas SMS/RJ e na SES/RJ; descentralização de vários procedimentos técnicos e administrativos, entre outras medidas - parecia indicar que a SES/RJ tinha dado os primeiros passos técnicos e políticos em direção ao SUS, adotando um outro modelo de atuação e se colocando como efetivo dirigente de políticas regionais e condutor de desafios para a mudança do modelo de saúde ${ }^{x}$. Porém, não foi o que ocorreu no período seguinte. 
Se for verdade que em um primeiro momento, de 1991 a 1992, a SES/ RJ atuou no sentido de sanar problemas e vencer obstáculos à descentralização", em um segundo momento, a partir de 1992, o estado passou por freqüentes interrupções nas gestões da SES/RJ, com trocas de vários secretários, que acabaram por adotar posturas críticas e contrárias à implementação do SUS ${ }^{10}$. Neste período, a SES/RJ teve uma atuação restrita na definição de políticas e projetos regionais (Parada, 1997).

No plano municipal, por sua vez, os municípios aprofundaram suas atribuições, formulando e implementando propostas de mudanças do modelo assistencial $^{11}$, reinvindicando a distribuição de Autorização de Internação Hospitalar - AIH - e de recursos ambulatoriais mais justos e fortalecendo o papel do COSEMS/RJ junto à SES/RJ e organismos colegiados de gestão (como, por exemplo, a Comissão Interinstitucional de Saúde - CIS - no âmbito estadual), passando a atuar de forma efetiva nas decisões de natureza político-operativa para a organização do sistema de saúde no estado.

O município do Rio, por sua vez, no período de 1991 a 1993, seguia uma linha de atuação isolada com relação à política de saúde no estado, com avanço na regionalização interna, porém, não participando regularmente das discussões mais gerais e sem disposição para assumir o comando único sobre as unidades federais e estaduais nele localizadas.

Em 1993, a promulgação da NOB SUS 01/93, apesar de continuar a utilizar os sistemas de informações de produção e faturamento para o repasse dos recursos federais de custeio da assistência ambulatorial e hospitalar (SIA-SUS e SIH-SUS), extingue a exigência convenial para o repasse e propõe uma modificação inédita na relação entre o nível federal e municipal, ao romper com a tradicional remuneração direta ao prestador utilizada pelo INAMPS. Os municípios habilitados em condição de gestão semiplena, após o cumprimento dos requisitos para habilitação previstos pela norma, passam a receber o montante dos recursos federais para o custeio ambulatorial e hospitalar através de transferência automática "fundo a fundo" (desembolso direto dos serviços prestados, através de créditos bancários às unidades públicas e privadas, credenciadas e conveniadas). Os mecanismos de transferência "fundo a fundo" representam a possibilidade de maior autonomia gestora pelo nível municipal, que passa a executar a totalidade de recursos assistenciais transferidos e a administrar os sistemas de informações de produção e faturamento do SUS, sem a interferência estadual.

$\mathrm{Na}$ conjuntura vigente, poucas eram as possibilidades de articulação política entre estado e municípios para a constituição da CIB no RJ. Somava-se 
aos aspectos acima levantados, a postura da instância estadual, avessa às necessidades das instâncias municipais, contrária ao processo de descentralização das ações e serviços de saúde em curso e às novas mudanças propostas inicialmente com as NOB SUS 01/91 e 01/92 e, posteriormente, com a NOB SUS 01/93.

A principal resistência encontrada na SES/RJ à época estava localizada na Subsecretaria de Municipalização ${ }^{12}$, que relutava em romper com o modelo de descentralização coordenado fundamentalmente pelo estado, observado no período do SUDS. Na verdade, a situação anterior à NOB SUS 01/91, privilegiava as SES como condutoras do processo de descentralização para os municípios no que tange à gestão financeira das ações de saúde. Com a NOB SUS 01/91 os estados perdem poder e com a NOB SUS 01/93, apesar de recuperarem alguns mecanismos de controle do repasse do recurso federal através da administração dos sistemas de informações SIA-SUS e SIH-SUS, acabam tendo que dividi-lo com os municípios no momento da pactuação dos tetos financeiros (atribuição das CIB) e através da vigência da transferência "fundo a fundo" nos municípios habilitados em gestão semiplena.

Para os municípios, por sua vez, a CIB/RJ representava não só a possibilidade de participar diretamente da discussão sobre o processo e os rumos da política de descentralização do SUS no estado, decidir sobre os critérios utilizados na definição dos tetos financeiros municipais para o repasse/transferência de recursos federais, como também um espaço formal, garantido pela NOB, para pleitearem a habilitação à condição de gestão semiplena e obterem sua aprovação - o que significava a possibilidade de uma maior autonomia no campo da gestão financeira.

Portanto, para os municípios, a implantação da $\mathrm{CIB} / \mathrm{RJ}$ era estratégica para garantir e acelerar os processos de habilitação à condição de gestão semiplena.

\subsection{A Definição dos Membros, a Câmara Técnica e o Processo Decisório}

Embora a CIB/RJ tenha sido criada oficialmente em 12 de julho de 1993, até o final deste mesmo ano não haviam sido sequer nomeados seus membros efetivos e suplentes. A nomeação ocorre somente em 25 de fevereiro de 1994, através da resolução $n^{0}$ 906/SES/RJ, sendo a CIB/RJ presidida pelo Dr. Jorge Alberto Penna Júnior, então Diretor Geral do Centro 
de Desenvolvimento Científico e Tecnológico da SES/RJ, e não, como sugerido pela própria NOB SUS 01/93, presidida pelo próprio Secretário de Estado de Saúde, Dr. Astor Pereira de Mello ${ }^{13}$. A CIB/RJ foi composta paritariamente por 16 membros titulares e suplentes oriundos dos municípios e da SES/RJ: seis secretários municipais de saúde da Diretoria do COSEMS/ $\mathrm{RJ}^{14}$ e das Vice-Presidências Regionais, pelo Secretário Municipal de Saúde do Rio de Janeiro e seu suplente ${ }^{15}$ e por oito chefias de primeiro e segundo escalão da SES/RJ' ${ }^{16}$.

Em 20 de julho de 1994 é editada a primeira deliberação da CIB/RJ já em pleno funcionamento. Esta deliberação cria uma Câmara Técnica (CT) de trabalho, formada por três representantes da SES/RJ e três representantes dos municípios, para assessorar a CIB/RJ na execução de atividades e serviços, de natureza técnica e administrativa. Embora a representação do COSEMS/RJ tenha sido caracterizada por uma atuação mais técnica ${ }^{17}$, devido ao próprio perfil dos representantes da SES/RJ, envolvidos diretamente com cargos do primeiro escalão da Secretaria ${ }^{18}$, sua atuação na CT, neste primeiro momento, foi, predominantemente, política.

$\mathrm{O}$ ano de 1994, em que pese ter sido marcado por intensas desconfianças e conflitos entre estado e municípios, proporcionou importantes conquistas para o aprofundamento do processo de municipalização no estado. Uma destas conquistas refere-se ao próprio processo de amadurecimento político e técnico dos secretários municipais de saúde que, através do COSEMS/RJ, participaram ativamente do processo de implantação da CIB/RJ, da elaboração da metodologia para definição dos tetos financeiros municipais e das primeiras habilitações às condições de gestão propostas pela NOB SUS 01/93.

Mediante a definição prévia da pauta, havia uma reunião da Diretoria do COSEMS/RJ com os membros da CIB/RJ para discussão dos diversos pontos elencados, de modo a garantir uma única posição de seus membros na CIB/RJ. Estas discussões e a própria organização interna do COSEMS/ $\mathrm{RJ}$ intensificaram e melhoraram qualitativamente a participação municipal nas reuniōes da CIB/RJ, que acabou por direcionar o foco da discussão.

Além disso, com a CIB/RJ, o COSEMS/RJ cresceu de importância no arranjo institucional da política de saúde do estado, aumentando gradativamente suas atribuições de representação e seu poder de decisão e direcionamento da política de saúde. Isto levou à necessidade cada vez maior de formar quadros técnicos de assessoria, aperfeiçoar sua estrutura organizacional e de agregar cada vez mais o conjunto de secretários municipais de saúde, melhorando sua articulação. 


\subsection{As Primeiras Pautas e o Conteúdo das Discussões}

A elaboração das pautas das reuniões da $\mathrm{CIB} / \mathrm{RJ}$ era inicialmente discutida e definida em conjunto por seus membros no final de cada reunião, de modo que, eram elencados previamente os pontos e traçadas as prioridades para discussão na próxima reunião.

As pautas das reuniões da CIB/RJ, até o final de 1994, centraram-se na discussão, julgamento e aprovação dos primeiros processos de habilitação municipais e na definição dos tetos financeiros, correspondentes ao repasse/ transferência dos recursos federais do SUS.

Foi desenvolvida uma primeira proposta para o cálculo dos tetos financeiros na CT. A proposta pautou-se na elaboração de um parâmetro físico de produção, baseado fundamentalmente na série histórica da produção ambulatorial, com as devidas correções e ajustes técnicos quando necessário. Para o cálculo do parâmetro físico da produção hospitalar, respeitou-se o critério de cotas de distribuição de $\mathrm{AIH}$ estipulado pelo MS, não se definindo, neste momento, um teto financeiro específico para a assistência hospitalar.

Frente à prioridade de aprovação dos pleitos a habilitação semiplena, a CT e a CIB/RJ priorizaram a discussão e a definição dos tetos dos municípios que pleiteavam esta condição de gestão. Para estes municípios, o teto financeiro representava o montante global de recursos federais transferidos para o custeio da assistência ambulatorial e hospitalar.

No entanto, a dificuldade em se obter informações repassadas pela SES/ RJ e a falta de consenso com relação aos tetos estipulados, impediram que estes fossem aprovados até o final de 1994, sendo a sua discussão e aprovação remetidas para o próximo ano, já em nova gestão da SES/RJ.

A segunda e última deliberação da CIB/RJ em 1994, publicada em 19 de dezembro, aprova os primeiros pleitos à habilitação municipal encaminhados a CIB. Foram aprovados sete pleitos à habilitação semiplena (Angra dos Reis, Duque de Caxias, Itaguaí, Niterói, Petrópolis, Resende e Volta Redonda), 14 pleitos à habilitação parcial e três à gestão incipiente, de um total de 81 municípios existentes na época. Para a aprovação dos primeiros pleitos municipais às condições de gestão da NOB SUS 01/93, seguiu-se a análise da documentação apresentada pelos municípios, segundo as exigências da norma. Embora tenham sido previstas visitas aos municípios para a verificação em loco do cumprimento de alguns requisitos, estas não chegaram a ser 
realizadas. Estipulou-se, então, que o controle do processo habilitação municipal seria feito através do acompanhamento do desempenho de sua gestão, realizado inicialmente pela SES/RJ.

\section{A CIB, Instrumento de Aproximação entre Estado e Municípios (Janeiro de 1995 a Agosto de 1996).}

\subsection{O Início da Nova Gestão da SES/RJ}

O início da nova gestão da SES/RJ foi marcado por grande expectativa de mudança e melhoria na relação entre estado e municípios. A entrada do novo Secretário de Estado de Saúde, Dr. Antônio Luiz de Medina, acompanhada de um quadro de profissionais oriundo da Secretaria Municipal de Saúde do Rio de Janeiro, com trajetória e respaldo técnico na área, abriu a possibilidade inclusive de um maior entrosamento entre a SES/RJ e a capital:

A principal diretriz política da nova gestão da SES/RJ era "resgatar a credibilidade da SES no RJ". Neste processo, a CIB/RJ foi um espaço considerado estratégico para alterar a imagem da SES/RJ frente aos municípios. Já que a relação formal, de pactuação e formação de acordos políticos setoriais entre estado e municípios, sob importantes aspectos decisórios da política de saúde, deveria acontecer na CIB/RJ, optou-se por fortalecer esta instância desativando-se a Subsecretaria de Municipalização e substituindo-a pela Secretaria Executiva da CIB/RJ.

Portanto, no entendimento da própria SES/RJ, a CIB/RJ daria maior poder aos secretários municipais de saúde e, por outro lado, a desativação da Subsecretaria de Municipalização diminuiria o papel de supervisão e contato direto, individual, com as SMS. A relação deveria se dar predominantemente entre estado e o órgão de representação dos secretários municipais de saúde no estado: o COSEMS/RJ.

Paralelamente ao fortalecimento da CIB/RJ, o fluxo decisório deveria ser organizado no interior da política de saúde do estado, através da implantação efetiva do Conselho Estadual de Saúde (CES) ${ }^{19}$.

Havia também uma preocupação por parte da SES/RJ em formular as estratégias da nova gestão com a participação das instituições acadêmicas com tradição na área de saúde pública. Assim, as diretrizes da nova gestão estadual contaram com a assessoria de técnicos vinculados a FIOCRUZ. 
Em linhas gerais, sete eram as propostas de ação da SES/RJ para o período de 1995 a 1998, que definiram vários programas e projetos, expressas no Plano de Saúde do Estado do Rio de Janeiro de 1995.

1. "Recuperação da rede de serviços própria visando: a descentralização administrativa das unidades com perfil de gerência municipal; a racionalização das unidades da zona oeste da capital e a implantação de unidades especializadas de referência estadual";

2. "Implementação do SUS através de: incentivo à implantação efetiva das condições de gestão pelos municípios já habilitados e estímulo à novas habilitaçōes, incluindo a própria SES/RJ em condição de gestão parcial; estabelecimento de consórcios intermunicipais de saúde, como instrumentos para regionalização e integração da assistência à saúde; qualificação da assistência de alto custo/alta complexidade, em especial, o sistema estadual de hemoterapia e hemoderivados e de transplante de órgãos";

3. "A implantação do Programa Médico de Comunidade ${ }^{20}$ através de convênios entre a SES/RJ e as SMS";

4. "A formação de Núcleos Regionais de Saúde Coletiva junto aos consórcios para implantação e acompanhamento dos Programas de Saúde nos municípios";

5. "O desenvolvimento da política de recursos humanos através de programas de formação, capacitação profissional e capacitação pedagógica";

6. "A profissionalização da gerência";

7. "O reforço dos Laboratórios de Produção e Pesquisa como o Noel Nutels e o Instituto Vital Brasil".

Outros projetos considerados prioritários e citados durante as entrevistas foram:

1. Reativação do Hospital da Posse, que era uma promessa de campanha do governador Marcelo Alencar, já que o hospital era apontado como a principal unidade da Baixada Fluminense, cuja desativação fazia com que as unidades municipais do Rio ficassem superlotadas;

2. Incorporação de novas modalidades de gestão nos hospitais estaduais;

3. Descentralização dos sistemas de informação do SUS;

4. Reativação e integração dos programas de saúde e ativação da vigilância sanitária que era praticamente inexistente na saúde coletiva. 
Para dar conta desses e de outros programas e projetos, foi realizada uma reforma na estrutura organizacional da SES/RJ, com: a criação da Coordenação Geral de Controle e Avaliação das redes de saúde municipais e estaduais; a reformulação funcional de estruturas preexistentes como a Subsecretaria de Saúde, reunindo as funções de gerenciamento das unidades estaduais e as funções de saúde coletiva e o Centro de Programação em Saúde (CPS), enquanto núcleo estratégico vinculado à Subsecretaria de Planejamento e Desenvolvimento (SPD) ${ }^{21}$.

$\mathrm{A}$ CIB/RJ passou a fazer parte do organograma oficial da SES, não mais vinculada a Subsecretaria de Municipalização (extinta na reforma), mas sim, ligada diretamente ao Secretário de Estado de Saúde através de sua Secretaria Executiva, como mostra a Figura 1.

No entanto, nem os programas e projetos, nem a reforma do organograma parecem ter sido suficientes para a delimitação de um novo papel para a SES/RJ. Pelo contrário, as diversas orientações dos projetos formulados para a nova gestão, pareciam oscilar de uma Secretaria com proposta mais inovadora, investindo em funçōes de planejamento, avaliação, coordenação e assessoria, para uma Secretaria com perfil mais conservador, mantendo suas antigas funções de saúde pública e incorporando funções gerenciais mal definidas na rede de serviços de saúde. O dilema central continuava a ser a falta de uma proposta clara de atuação para a SES/RJ, coerente com as novas demandas da política de saúde vigente. 
FIGURA 1- ORGANOGRAMA DA SES/RJ - 1995

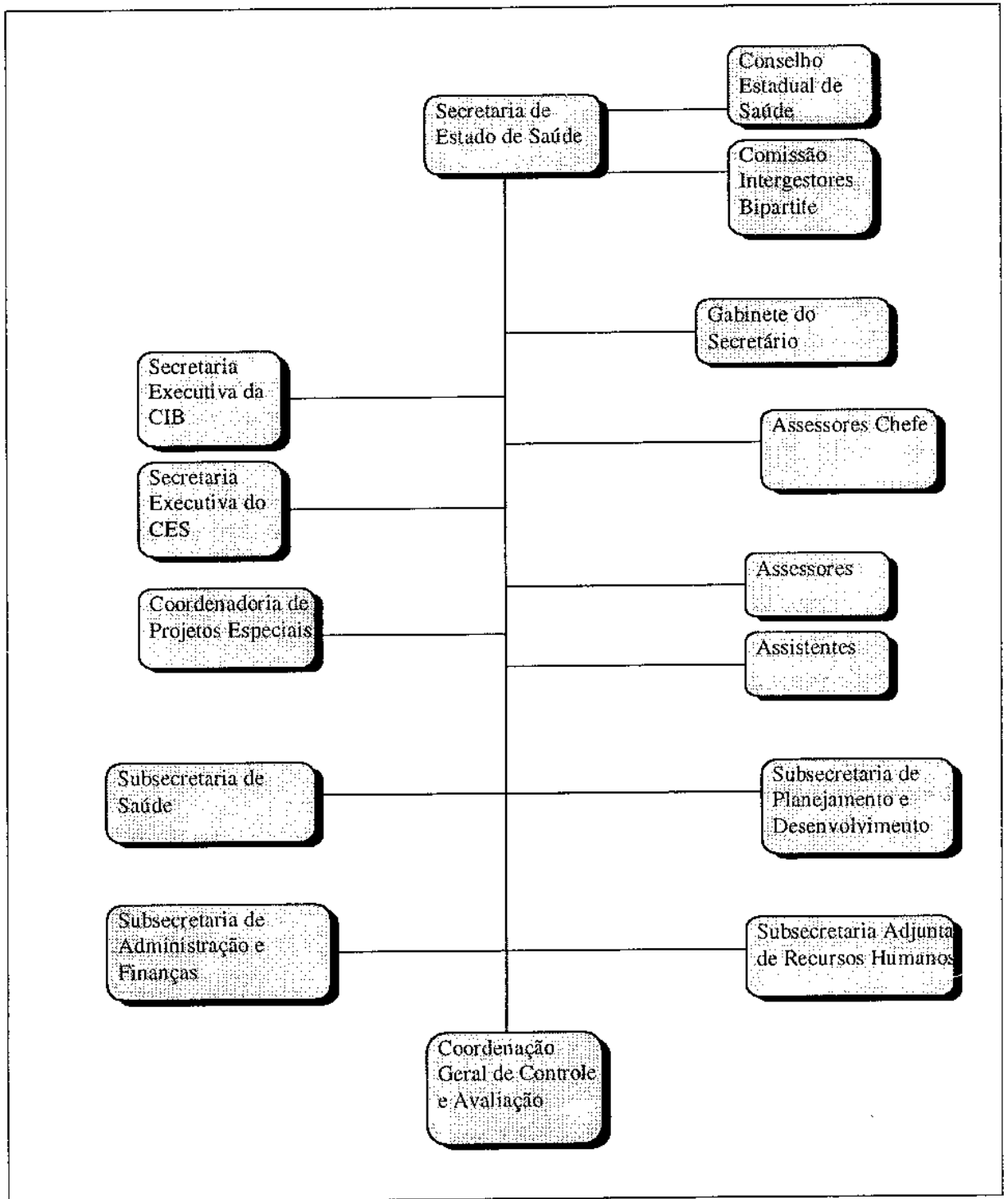

Fonte: SPD/SES/RJ 


\subsection{Representação e Processo Decisório}

No que se refere ao funcionamento da $\mathrm{CIB} / \mathrm{RJ}$ no período, este foi marcado, majoritariamente, pela relativa estabilidade e equilíbrio na relação estado e municípios, pela formação de acordos políticos e consenso no processo de tomada de decisões e por deliberações marcadas pelo esforço da cooperação de ambas as partes.

Pode-se perceber a necessidade cada vez maior de negociação e formação de acordos políticos no processo decisório desta instância gestora. Isso porque foi implantada a exigência formal, normativa, do parecer e aprovação da CIB/RJ para a implementação de uma série de medidas, com o paralelo aumento da importância e participação do COSEMS/RJ enquanto órgão de representação dos secretários municipais de saúde, com posicionamento autônomo e independente do estado nas discussões travadas na CIB/RJ,. É a partir desta época, que se consolida na $\mathrm{CIB} / \mathrm{RJ}$ a prática de deliberação por consenso. Nenhuma decisão, desde então, é tomada através do voto.

Em grande parte, a postura do Secretário de Estado de Saúde, preocupado em resgatar a credibilidade da SES/RJ junto aos municípios e mais sensível às demandas e propostas dos secretários municipais de saúde, foi responsável pelo bom andamento das discussões e pelos resultados positivos do processo de negociação política na $\mathrm{CIB} / \mathrm{RJ}$. Destaca-se a presença do Secretário de Estado de Saúde na maioria das reuniões realizadas e o respeito por parte da SES/RJ às decisões tomadas na CIB/RJ, postura bem diferente do período anterior.

Com relação à origem dos membros da SES/RJ, esta se manteve basicamente a mesma até o final de 1998. Estavam presentes funcionários do primeiro e segundo escalão da SES/RJ, com destaque para a Subsecretaria de Planejamento e Desenvolvimento do Estado e em segundo plano para a Subsecretaria de Saúde, devido aos próprios temas ou assuntos abordados durante as reuniões, a regularidade de suas participações e a influência de suas intervenções.

No que se refere ao COSEMS/RJ, sua composição era proveniente dos secretários membros da Diretoria ${ }^{22}$ da nova chapa recém-eleita e das VicePresidências Regionais. A mudança na Diretoria não trouxe mudanças substanciais na representação do COSEMS/RJ com relação a 1994.

Outra característica marcante do período, refere-se à importância alcançada pela CT para a discussão, avaliação e encaminhamento de propostas à $\mathrm{CIB} / \mathrm{RJ}$. Todos os assuntos em pauta ou processos remetidos à 
CIB/RJ, que necessitassem de uma avaliação técnica, baseada em análises de informações e estudos apresentados principalmente pela SES/RJ, ou que extrapolassem o tempo da reunião da $\mathrm{CIB} / \mathrm{RJ}$ eram remetidos à $\mathrm{CT}$.

Com base nas discussões da CT, buscava-se os acordos e os consensos necessários ao processo decisório da $\mathrm{CIB} / \mathrm{RJ}$ e à implementação de propostas aprovadas.

Foram criados rotinas e fluxos, que exigiam o parecer da CT antes de seu encaminhamento a CIB/RJ propriamente dita $^{23}$, para o encaminhamento de processos municipais relativos ao credenciamento e cadastramento de serviços de saúde e à habilitação às condições de gestão propostas pela NOB vigente e para as propostas de elaboração e revisão de critérios para a alocação dos recursos federais. Isso fez com que, na prática, a CT tivesse um peso muito grande no resultado das discussões e na aprovação de processos e propostas encaminhadas à $\mathrm{CIB} / \mathrm{RJ}$. O perfil de seus membros ${ }^{24} \mathrm{fez}$ crescer o caráter mais técnico das reuniões e ajudou a diminuir conflitos políticos. Um fato interessante é que a CIB jamais deliberou de forma diferente da sugestão da CT.

Os membros da CT eram, na sua maioria, membros suplentes da CIB/RJ. A participação dos membros da CT na maior parte das reuniões da CIB/RJ, mesmo naquelas em que os membros efetivos estavam presentes, fez crescer ainda mais o seu poder de influência ${ }^{25}$.

A participação nas reuniões variou ao longo do tempo, segundo a origem da representação. Devido ao caráter "aberto" das reuniões, ressalta-se o grande número de representantes dos municípios, na maioria secretários municipais de saúde, que participaram, já nesta fase, como ouvintes nas reuniões, sem direito a voto, mas com direito a voz. É possível ainda identificar a presença constante do representante do MS, a ausência do representante do CES e a participação de representantes da Assembléia Legislativa do Estado na reunião que discutiu sobre a mortalidade materna no estado.

Considerando-se o número total de participantes nas reuniões (incluindo membros titulares, suplentes e ouvintes), a média de participação dos municípios nas 21 reuniões, ordinárias e extraordinárias, realizadas neste período, foi de dez representantes por reuniăo, enquanto o estado apresentou uma média de seis representantes por reunião. 


\subsection{Os Principais Pontos de Pauta e o Conteúdo das Discussões}

Com relação aos principais pontos de pauta, também neste segundo período da CIB/RJ, predominou a discussão sobre a definição da metodologia para o cálculo dos tetos financeiros municipais e fixação dos mesmos. A definição e aprovação dos tetos financeiros eram prioritárias para a implementação da gestão semiplena, como relatado anteriormente. Assim, foram feitas várias reuniões da CT para discussão e delimitação de uma proposta, sustentável tecnicamente, que pudesse contemplar a maioria dos municípios. As propostas discutidas na CT foram encaminhadas fundamentalmente por técnicos do segundo escalão da Subsecretaria de Planejamento e Desenvolvimento da SES/RJ ${ }^{26}$.

Devido a urgência da definição dos tetos financeiros globais dos municípios em semiplena, estes foram aprovados em abril de 1995, mantendo-se os tetos fixados no final de $1994^{27}$ com uma redução $2,26 \%$, correspondente ao corte financeiro sofrido pelo estado, mas com a promessa assumida pela SES/RJ de revisão dos mesmos em 60 dias. As transferências "fundo a fundo" para os primeiros municípios habilitados em semiplena foram efetivadas a partir de abril de 1995, mesmo estando garantidas as condições para as transferências via fundos de saúde desde novembro de 1994.

Por sua vez, a proposta final da distribuição dos tetos ambulatoriais, primeira aprovada na nova gestão da SES/RJ para o conjunto dos municípios, incluindo para aqueles já em gestão semiplena ${ }^{28}$, só foi homologada em reunião extraordinária da CIB/RJ em 14 de agosto de 1995, com o compromisso de revisão e readequação trimestral, vigindo a partir de setembro de 1995 até o início de 1998. Em que pesem os elogios e o apoio por parte do COSEMS/RJ ao processo de negociação e pactuação dos tetos financeiros conduzido pela SES/RJ, a fixação dos tetos se deu após uma negociação de seis meses, com várias ponderações e revisões da SES/RJ e dos secretários municipais de saúde.

As dificuldades enfrentadas para a fixação dos tetos financeiros e os conflitos evidenciados entre o gestor estadual e os gestores municipais de saúde ocorreram devido: a escassez dos recursos distribuídos e a dificuldade de satisfazer as necessidades de produção apresentadas pelos municípios; às pressões e disputas por recursos entre os próprios gestores municipais; as desconfianças com relação a veracidade dos ensaios apresentados pela SES/ $\mathrm{RJ}$; o baixo gasto em saúde realizado pelo estado. 
A metodologia, inicialmente aprovada para o cálculo dos tetos ambulatoriais, foi baseada na definição de parâmetros físicos de produção para os diversos conjuntos de procedimentos ambulatoriais contidos na tabela SIA-SUS, definidos de acordo com a série histórica da produção ambulatorial do estado, observada no segundo semestre de 1994. Estes parâmetros foram então multiplicados pela população de cada município no ano de 1995 , com a devida correspondência financeira para definição do teto ambulatorial. Em seguida, com base no cadastro de serviços ambulatoriais, foram definidos quais os conjuntos de procedimentos que os municípios podiam executar ou não, o chamado "faz" e "não-faz". Os recursos correspondentes aos procedimentos que não podiam ser executados no município, por falta de serviços compatíveis em seu cadastro ambulatorial, foram redistribuídos da seguinte forma: $60 \%$ foram alocados na mesma região do município (repartidos proporcionalmente à produção de cada município com capacidade instalada dentro da região) e os $40 \%$ restantes, distribuídos pelos outros municípios do estado que possuíssem a capacidade instalada para execução dos procedimentos, também proporcionalmente à sua produção no restante do estado, ou seja, fora da região.

Esta metodologia - de cálculo complexo -, tinha por objetivo realocar os recursos para os municípios-pólo, diminuindo os problemas de ausência de recursos, ou de sua não previsão para assistência da migração intermunicipal. No entanto, foram muitas as dificuldades encontradas com a nova metodologia. Muitas delas se deve a própria ausência de informatização do SIA-SUS e de dados de produção confiáveis em todo o estado.

Um outro problema encontrado foi a impossibilidade da definição da origem e destino do recurso por cada gestor municipal. Isto é, o gestor municipal não tinha autonomia para decidir o destino do seu recurso "nãofaz", nem mecanismos para exigir o atendimento da referência nos municípios-pólo. Este problema, apontado como uma das principais falhas da proposta, foi remetido para discussão e posterior revisão.

Pautada nesta reivindicação, a CT debruçou-se na discussão de uma nova metodologia, apresentada oficialmente a CIB/RJ em março de 1996 e formulada principalmente no âmbito da $S E S / \mathrm{RJ}^{29}$, que previa um novo ordenamento para o recurso "não-faz". Através de novos critérios de realocação do recurso, este seria destinado pelo próprio gestor municipal para um outro município, contendo um serviço de sua preferência, através de uma ficha específica: a Ficha de Referência Intermunicipal (FRI). $\mathrm{Na}$ FRI, o gestor municipal explicitaria uma pactuação com outro município, 
permitindo a retirada de um recurso para a realização dos procedimentos de média e alta complexidade de seu teto, não passíveis de execução em seu próprio município. Como a revisão do cadastro de serviços ambulatoriais seria feita trimestralmente, o município que fosse adquirindo novos recursos e aperfeiçoando sua capacidade instalada, poderia pleitear a realocação do recurso financeiro, transferindo-o novamente para o seu próprio teto.

Apesar de não garantir o atendimento e não prever a fiscalização da execução do recurso, a FRI era uma proposta que dava visibilidade ao recurso realocado entre os municípios e estimulava uma negociação intermunicipal. Foram feitas várias reuniões regionais para a apresentação da proposta pelo estado e, posteriormente, cada região se reuniu isoladamente, com a presença somente dos secretários municipais de saúde e técnicos municipais, visando estimular o estabelecimento das referências e a pactuação do recurso intra-regionalmente.

Com a FRI, os municípios-pólo poderiam perder recurso, na medida em que o recurso não seria mais realocado automaticamente no seu teto como o proposto na metodologia vigente. Estes teriam que negociar com os municípios vizinhos a execução de determinados procedimentos, o que aumentaria, em tese, a competitividade entre os municípios prestadores.

No entanto, a alta concentração de serviços de média e principalmente de alta complexidade no estado, fez com que, na prática, os municípios-pólo mantivessem seu poder de barganha e influência na negociação regional. A curto prazo, não havia possibilidade de uma maior desconcentração do recurso no estado, pois as opções de referência mantinham-se as mesmas .

O boicote feito por alguns municípios-pólo e por outros municípios de pequeno porte, que não viam na proposta perspectivas de resolução de seus problemas de referência, foi um dos fatores relacionados à não implementação da FRI até o final do governo Marcelo Alencar ${ }^{30}$.

As divergências com relação à pertinência e adequabilidade da proposta para o conjunto dos secretários municipais de saúde foram discutidas no COSEMS/RJ. A falta de consenso entre os secretários e a dificuldade de elaboração de uma metodologia para definição dos tetos financeiros foi evidente.

Outro fator foi a falta do correto entendimento das funções da FRI pelos secretários municipais de saúde, devido à incapacidade do estado em defender e apresentar corretamente a finalidade da proposta: 
A FRI não foi criada com a finalidade de garantir a referência, mas sim de servir como um instrumento de programação dos tetos financeiros, capaz de dar maior visibilidade e transparência aos recursos transferidos entre os municípios.

Com relação à assistência hospitalar, foi desenvolvido um teto físico com base nas cotas de distribuição da $\mathrm{AIH}$, fixadas em $9 \%$ da população/ano, sendo parcela deste recurso destinada ao estado para ser utilizada em caso de epidemias, catástrofes e sazonalidade. A novidade da proposta estava na distribuição de cotas para o conjunto de municípios, mesmo para aqueles que não possuíam leitos hospitalares, com o objetivo de estimular a câmara de compensação de $\mathrm{AIH}$ entre os municípios e diminuir a dependência com relação aos pólos.

As discussões sobre teto financeiro foram, sem dúvida, os principais pontos de pauta, tanto da CT como da CIB/RJ, nesta segunda fase de seu funcionamento. No entanto, a abrangência dos assuntos discutidos na CIB/ RJ ampliou significativamente. Foi inaugurada nesta fase uma sistemática de organização das reuniões da CIB/RJ, iniciadas com o relato e aprovação da ata da reunião anterior, seguida de informes da política de saúde, em âmbito federal, estadual e municipal ${ }^{31}$.

\section{A Transição no Relacionamento entre Estado e Municípios (Setembro de 1996 a Abril de 1997)}

\subsection{As Mudanças na Relação entre Estado e Municípios}

Apesar da aproximação entre estado e municípios, observada no período de janeiro de 1995 a agosto de 1996, já nesta época, começam a se configurar determinadas características no relacionamento entre estado e municípios e no próprio funcionamento da $\mathrm{CIB} / \mathrm{RJ}$, que tiveram influência marcante para os períodos subseqüentes: a fase de transição (setembro de 1996 a abril de 1997) e de conflito aberto (maio de 1997 a dezembro de 1998).

Durante esta época, é o COSEMS/RJ que cada vez mais assume a responsabilidade de articular e integrar os secretários municipais de saúde e mediar a relação entre estado e municípios em discussões bastante complexas, como a definição do teto financeiro para a transferência do recurso federal. Esta função se complica, frente a diversidade de municípios com realidades, visões e posturas políticas distintas na área da saúde e à alta rotatividade de secretários municipais de saúde ${ }^{32}$. 
Por outro lado, em que pese o fortalecimento da prática de pactuação entre os membros da CIB/RJ é o estado que começa a estabelecer os pontos de pauta, quer seja por iniciativa própria, quer seja por exigência do MS e direcionar as discussões da CIB/RJ. Poucos são os momentos em que os municípios definem, previamente à reunião, um ponto de pauta. Geralmente, esses são trazidos no início das reuniões como sugestões de inclusão ou referidos como questões pendentes de reuniōes anteriores.

Um outro aspecto refere-se ao fortalecimento progressivo dos representantes da SES/RJ na CIB/RJ, técnicos do primeiro e segundo escalão da SES/RJ, e o afastamento progressivo da figura do próprio Secretário de Estado de Saúde das discussões travadas a partir de outubro de 1995 , evidenciado pela irregularidade de sua participação nas reuniões (ausências ou atrasos constantes) e pela perda da liderança do processo de negociação. A liderança progressiva assumida pelos técnicos da SES/RJ acaba por alterar o relacionamento entre estado e municípios. Paulatinamente, aparecem os conflitos políticos e crescem as estratégias de manipulação das discussões travadas na $\mathrm{CIB} / \mathrm{RJ}$ pelo estado.

Cabe ainda destacar, as crescentes divergências políticas entre os municípios (incluindo a capital) e o estado, no plano geral e específico do setor saúde. Estas divergências estavam associadas ao plano político-partidário, à delimitação das competências do estado e dos municípios no sistema de saúde e aos próprios projetos e postura política desenvolvidos pela SES/RJ no decorrer do período.

Com relação à participação do nível federal nas reuniões da CIB/RJ, esta não foi capaz de resolver algumas questões pendentes com relação à integração do conjunto de serviços federais no município do RJ do ponto de vista físico e financeiro. As unidades federais continuaram a funcionar autonomamente ao restante do sistema de saúde.

O final do período encerra, portanto, uma configuração bastante complexa, com limites bastante tênues para o processo de negociação política dos assuntos discutidos e aprovados na CIB/RJ.

A fase de transição (ou ruptura) do período de relativa estabilidade para um período de conflito mais aberto entre estado e municípios, pode ser delimitada pelo primeiro pleito de habilitação à gestão semiplena encaminhado pelo município do Rio de Janeiro e pelo processo de negociação e aprovação dos projetos a serem contemplados com os recursos de investimento 
do projeto REFORSUS. Esta fase, caracterizou-se principalmente pela quebra da confiança com relação as ações e propostas encaminhadas pelo estado observada a partir de então.

O desgaste político sofrido pela SES/RJ no período foi decorrente de uma série de fatores, entre eles, alguns destacados pelos entrevistados na pesquisa foram: a forma como foi conduzida a discussão sobre o processo de habilitação do município do Rio; a ausência de critérios uniformes no julgamento dos processos de habilitação municipais; as acusações com relação ao privilégio do financiamento de unidades estaduais no REFORSUS; a falta de transparência e uniformidade no processo de avaliação das propostas de financiamento do REFORSUS; a ausência de argumentações respaldadas por estudos de necessidades e de propostas fundamentadas por um plano estadual de saúde com o objetivo de superar as desigualdades e desequilíbrios regionais; a postura adotada pela SES/RJ na condução das discussões e na formação dos acordos políticos na $\mathrm{CIB} / \mathrm{RJ}$; a divergências com relação às políticas e projetos encaminhados pela SES/RJ.

\subsection{O Processo de Habilitação do Município do Rio à Condição de Gestão Semiplena}

O primeiro processo de habilitação à gestão semiplena foi enviado pelo município do Rio a CIB/RJ em julho de 1996. O processo, avaliado inicialmente pela $\mathrm{CT}$, posteriormente, submeteu-se a CIB/RJ para análise e aprovação em duas reuniões subseqüentes: uma extraordinária, realizada em 30 de setembro de $1996^{33}$ e outra ordinária, realizada em 07 de outubro de 1996.

Nas reuniões, os conflitos em torno da aprovação do processo ficaram polarizados entre as argumentações a favor, apresentadas pelo município do Rio e pelo COSEMS/RJ e relacionadas à oportunidade e importância da habilitação do Rio para o aprofundamento do processo de municipalização em nível nacional ${ }^{34}$ e os argumentos contra, apresentados pelo estado, relacionados principalmente: à existência de uma série de pendências com relação aos requisitos formais para a habilitação em gestão semiplena previsto pelas instruções normativas da NOB SUS 01/93 35 ; à falta de uma proposição com relação à municipalização de unidades estaduais com perfil municipal; à ausência de garantias do atendimento às referências dos outros municípios, principalmente no que se refere ao alto custo/alta complexidade da assistência ambulatorial e à ausência de uma política de recursos huma- 
nos formulada em conjunto com os outros municípios; à indefinição com relação à inclusão do recurso orçamentário das unidades federais, existentes no município do Rio, no teto financeiro do estado.

A discussão com relação a um processo de habilitação municipal foi remetida de forma explícita, pela primeira vez na CIB/RJ, do campo técnicoburocrático, respaldado pelo cumprimento dos requisitos normativos, para o campo político, onde ficaram claras as divergências e disputas de poder, com relação aos papéis desempenhados pelas instâncias subnacionais de governo no sistema de saúde. Até então, os conflitos eram manifestados fundamentalmente no momento da definição do teto financeiro.

A falta do consenso em relação à questão e dificuldades para a formação de acordos políticos em torno de uma proposta, provocou o adiamento da decisão para uma reunião a ser realizada com uma equipe da SMS do RJ e da SES/RJ, onde o COSEMS/RJ entraria como mediador. No entanto, a permanência da situação fez com que o Secretário Municipal de Saúde do RJ retirasse o processo, interrompendo o curso das discussões. A decisão do Secretário impediu com que o processo, neste momento, seguisse seu andamento formal, previsto pela política de saúde. Nos casos de falta de consenso ou impossibilidade de acordos, a NOB SUS 01/93 prevê o encaminhamento da discussão e decisão para o CES e, na ausência deste, para a CIT.

A solicitação de habilitação pelo município do RJ e os impedimentos colocados pelo estado marcam o início de uma nova fase de politização das discussões da CIB/RJ, diferentemente daquela observada durante a implantação da CIB/RJ (1994). Neste momento, o estado possui uma participação mais ativa e uma influência maior no rumo das decisões tomadas. A CT, que no primeiro momento da gestão Medina, teve uma influência importante nos processos de negociação política e tomada de decisão da CIB/RJ, foi esvaziada de suas funçōes pela falta de competência para o julgamento sobre os conteúdos das discussões em pauta.

A proximidade das eleiçōes para Prefeito fez com que a habilitação do município do RJ ganhasse uma importância muito grande para a campanha eleitoral. As questões políticas envolvidas não podiam ser resolvidas no espaço da $\mathrm{CT}$, pois não havia análises e propostas técnicas que pudessem superá-las. 


\subsection{A Discussão sobre a Alocação dos Recursos do Projeto REFORSUS}

Uma das discussões de maior polêmica na CIB/RJ, ponto de pauta de um número significativo de reuniões, ordinárias e extraordinárias, motivando a participação de vários secretários municipais de saúde, foi o projeto de Reforço à Reorganização do SUS (REFORSUS). Enquanto uma iniciativa do Ministério da Saúde, o REFORSUS representou o primeiro momento em que CIB/RJ discutiu e deliberou sobre critérios para distribuição de recursos de investimentos provenientes do nível federal entre os municípios.

Apesar dos investimentos do componente I do REFORSUS (Apoio à Melhoria da Capacidade e da Eficiência do SUS), de uma forma global, terem sido objeto de discussão na CIB/RJ, somente os investimentos da Área Programática I (Readequação Física e tecnológica da rede assistencial, com ênfase nas seguintes áreas: assistência ao parto, puerpério e perinatal; assistência à urgência e emergência em grandes áreas urbanas), por representarem maior diversificação das linhas de investimento e maior possibilidade de apresentação de propostas de conteúdo, valor e origens distintas, suscitaram disputa pela definição final da alocação do recurso durante o período analisado.

Entre outras funções, o CPS/SPD/SES/RJ ficou com a responsabilidade principal pela avaliação das propostas em nível estadual referentes à AP I do componente I. A avaliação foi composta por duas etapas. A primeira, referente à aplicação de critérios de elegibilidade, constituiu-se da verificação do cumprimento das exigências específicas da convocatória do projeto e da coerência da proposta com os princípios gerais do REFORSUS. As propostas consideradas elegíveis, passaram, em seguida, por um processo de avaliação mais detalhado, em que foram aplicados critérios de classificação de prioridades, segundo a pontuação dos indicadores técnicos recomendados para as áreas consideradas. Após elaborar um ranking das propostas, a SES/RJ encaminhou-as para avaliação e aprovação na CIB/RJ. A discussão sobre a alocação destes recursos do REFORSUS acabou por assumir, na CIB/RJ um conteúdo político de difícil solução, que será descrito a seguir.

Na primeira reunião da CIB/RJ em que se discutiu sobre o REFORSUS, apresentou-se o montante do recurso da AP I do componente I destinado ao Rio de Janeiro. O recurso de $\mathrm{R} \$ 26.500 .000,00$ era inferior ao valor total dos 394 projetos, equivalente à $\mathrm{R} \$ 235.596 .409,00$, aprovados como prioridades de investimento para o estado em outubro de 1995 e encaminhados 
à Brasília através do Plano de Investimento do Estado ${ }^{36}$. A estratégia proposta pelo estado para adequar o Plano de Investimento ao recurso disponível do REFORSUS, foi a de redefinir as prioridades de investimento para o estado, excluindo do Plano os projetos que não se adequavam às exigências do REFORSUS, que iriam ser contemplados com recursos de áreas programáticas específicas ou de outras fontes de investimento. A decisão final das prioridades de investimento deveria ser então homologada pela CIB/RJ, como uma de suas atribuições previstas no REFORSUS.

Assim, foram excluídos inicialmente do Plano de Investimento os projetos referentes aos hospitais federais, aos hospitais universitários (excetuando-se aqueles que contemplassem as áreas de emergência e assistência maternoinfantil), às unidades de hemoterapia e hematologia, aos laboratórios de saúde pública, ao Programa de Saúde da Família (PSF), à compra de equipamentos exclusivos, às obras em unidades estaduais já concluídas ou orçadas e aos projetos com valor inferior à $\mathrm{R} \$ 50.000,00$. Mesmo aplicando tais critérios de exclusão, o valor total dos projetos continuava ultrapassando em mais de R\$ 8.000.000,00 os recursos previstos no REFORSUS para o estado.

$\mathrm{Na}$ proposta, os recursos seriam assim distribuídos: Maternidade/ R \$3.000.000,00; Emergência/ R $\$ 4.000 .000,00$; Maternidade do Hospital Pedro Ernesto/ R $\$ 1.000 .000,00$; Projetos para unidades estaduais/ R $\$ 6.000 .000,00$ e $R \$ 21.212 .000,00$ para obras no Hospital Estadual de Saracuruna ( R \$16.500.000,00) e outras obras inacabadas nos municípios. Nota-se que, na proposta de revisão das prioridades apresentada pelo estado à $\mathrm{CIB} / \mathrm{RJ}$, os recursos destinados às unidades estaduais $(\mathrm{R} \$ 22.500 .000,00)$ representavam cerca de $64 \%$ do total dos recursos.

Posteriormente, optou-se por definir na CIB/RJ, uma lista de projetos distribuídos por região, segundo unidades prestadoras, contidos em uma declaração de prioridades de investimento a serem encaminhados à Unidade de Gerência de Projeto do MS (UGP/MS). A declaração aprovada não continha o valor dos projetos elencados.

No entanto, paralelamente à aprovação e encaminhamento da listagem dos projetos, definiu-se que todos os municípios poderiam encaminhar propostas, independentemente de seus projetos estarem previstos ou não como prioridades de investimento, já que, segundo orientação do próprio MS, os recursos, inicialmente alocados para o estado do Rio, poderiam ser aumentados de acordo com a capacidade de execução dos projetos. Além disso, durante a avaliação das cartas-consultas e dos subprojetos pela SES/RJ 
(Brasil, MS, SAS, 1996), alguns projetos priorizados poderiam ser classificados como inelegíveis para o financiamento do REFORSUS.

Este fato, associado às sucessivas prorrogações dos prazos de entrega dos projetos estipulados pelo MS, fez com que o número de projetos encaminhados à SES/RJ crescesse enormemente, superando em muito a lista de prioridades aprovadas na $\mathrm{CIB} / \mathrm{RJ}$ anteriormente. Até a data final marcada para a entrega dos projetos (28/02/1997) foram recebidos pela SES/RJ 128 projetos, sendo 28 considerados inelegíveis.

No decorrer do processo de avaliação dos projetos enviados à SES/RJ, muitas pendências foram solucionadas em tempo hábil de modo a aumentar o número de municípios com possibilidade de obtenção do financiamento do REFORSUS. Uma estratégia adotada pela CIB/RJ, neste período, foi a de aprovar uma série de municípios com pleito de habilitação à gestão plena da atenção básica pela NOB SUS 01/96 para efeito do REFORSUS, segundo deliberação da CIB/RJ no 08/97 de 24/02/97. As habilitações foram aprovadas, inicialmente, com exigências processuais, pois ainda não estavam estabelecidos todos os instrumentos normativos necessários para a informação dos processos à habilitação na NOB SUS 01/96, sendo estipulado um prazo para a solução das pendências mais imediatas. Ao todo, 34 municípios habilitaram-se no modelo plena da atenção básica, sendo quatro destes municípios recém-emancipados ${ }^{37}$.

Embora sem maiores repercussões para o modelo vigente de repasse, transferência e gestão dos recursos do nível federal, já que ainda prevaleciam os mecanismos estipulados pela NOB SUS 01/93, esta medida aumentou de 24 municípios habilitados em algum modelo de gestão no estado, para 58 , de um total de 91 municípios existentes à época e evidenciou a possibilidade de agilização do julgamento e aprovação dos processos de solicitação à habilitação municipal.

A segunda fase do processo de avaliação dos projetos encaminhados, que consistiu da pontuação e hierarquização das propostas, foi uma fase de intenso conflito e disputas pelos recursos. Foram feitas uma série de críticas em relação a transparência do processo de avaliação realizado pela SES/RJ, ao privilégio das unidades estaduais e à pontuação apresentada à CIB/RJ para aprovação.

A pontuação e a hierarquização das propostas foram então revistas em reuniöes da CT, onde estava presente um número significativo de secretários municipais de saúde e técnicos das respectivas secretarias. Nestas reuniões optou-se pela repontuação das propostas de modo a contemplar a maior 
parte dos projetos possíveis, tentando-se, ao mesmo tempo, distribuir mais equilibradamente os recursos nas diversas regiões do estado.

A pontuação final aprovada não respeitou a lista de prioridades de projetos definida inicialmente pela CIB/RJ e nem, tão pouco, foi respaldada por estudos ou informações apresentadas pela SES/RJ, o que suscitou uma série de dúvidas pelos municípios quanto a pontuação e manteve o grau de disputa e insatisfação por parte dos secretários municipais de saúde.

Segundo relato da Subsecretária de Planejamento e Desenvolvimento do Estado descrito em ata, a pontuação final da CIB/RJ obedeceu a vários critérios:

1- Priorização dos projetos das regiões do estado com maior déficit de capacidade instalada, grande densidade populacional e com piores indicadores de saúde, como foi o caso da Baixada Fluminense, São Gonçalo e Itaboraí.

2- Priorização dos hospitais de caráter regional com capacidade de atender a mais de um município como foi o caso de Rio Bonito.

3- Priorização dos municípios sem leito como Pinheiral, Paty de Alferes, Cardoso Moreira e São Sebastião do Alto.

4- Priorização dos leitos de maternidades nas duas regiões do estado com maiores índices de mortalidade materna e com maiores taxas de realização de cesariana como as regiões do Médio-Paraíba e Centro-Sul.

5- Priorização das urgências e emergências nas regiões da Baixada Litorânea e na Baía da tha Grande, devido aos altos índices de acidentes automobilísticos nas épocas de verão e feriados.

6- Priorização da assistência neonatal na região Metropolitana.

7- Priorização dos leitos de maternidade na zona oeste do município do Rio de Janeiro.

Os recursos do REFORSUS, no entanto, não corrigiram distorções regionais na área de emergência e materno-infantil como intencionado pelo MS e como apontado pela SES/RJ. A lista de critérios citados acima serviu muito mais como justificativa para a classificação e aprovação final das propostas, do que como base para orientar o processo de avaliação e pontuação.

Por outro lado, a fragmentação dos recursos em múltiplos projetos acabou por dificultar a execução dos projetos, já que a SES/RJ não possuía estrutura gerencial para o acompanhamento de todos aqueles aprovados. 
O resultado é que o RJ apresenta-se como um dos estados mais atrasados na execução dos recursos.

A falta de um plano estadual de saúde informado pelo diagnóstico dos desequilíbrios da oferta e produção dos serviços de saúde no estado, pode ser apontada como um dos fatores responsáveis pela incapacidade de alocação do recurso REFORSUS, de forma a dar conta dos desequilíbrios regionais. No REFORSUS, nasceram projetos individuais, dos municípios, desancorados das necessidades das regiões, mas sim, pautados nas necessidades dos municípios em função de suas realidades específicas.

A ausência deste diagnóstico, de um plano regional de investimento para o estado e a insuficiência dos recursos para dar conta dos desequilíbrios regionais contribuíram para que a $\mathrm{CIB} / \mathrm{RJ}$ priorizasse os critérios técnicos ou as exigências de elegibilidade apresentadas pelo MS para a aprovação individual das propostas. A pontuação final aprovada, em que pese a tentativa de repontuar os projetos diminuindo a concentração do recurso, esteve sujeita a conflitos de interesses e não foi suficiente para corrigir as distorções.

\subsection{A Representação no Período}

Vale ressaltar que, durante a discussão da alocação dos recursos do REFORSUS, o número de participantes oriundos dos municípios nas reuniões da CT e da CIB/RJ aumentou significativamente e permaneceu bastante elevado durante toda a fase subseqüente. A média de participação dos municípios nas 12 reuniões, ordinárias e extraordinárias, realizadas nesta fase foi de 12 representantes por reunião, superior ao período anterior, mantendose a média de participação do estado em 6 representantes por reunião. Este momento representou para muitos secretários ${ }^{38}$ a possibilidade de conhecer instrumentos e normas do funcionamento da política de saúde no âmbito nacional e estadual e o início de sua participação e engajamento em fóruns de pactuação mais amplos, como o COSEMS/RJ e a própria CIB/RJ.

Identifica-se, nesta fase, a mudança do Secretário de Estado de Saúde em fevereiro de 1997, tendo assumido a Secretaria o Dr. Ivanir Martins de Mello, a inserção dos novos secretários municipais de saúde das Prefeituras recém-eleitas e dos municípios recém-emancipados ${ }^{39}$ e a eleição da nova Diretoria do COSEMS/RJ em março de 1997. No entanto, no que se refere à representação municipal, não houve mudanças significativas na composição da Diretoria do COSEMS/RJ e nos membros da CIB/RJ no período de transição. A mudança na Diretoria do COSEMS/RJ, ocorrida em março de 
1997, teve repercussões na condução das discussões que se seguiram na CIB/RJ a partir de maio de 1997.

Um outro ponto que merece destaque refere-se à irregularidade da participação do representante do MS no período, diferentemente do período anterior e que se manteve no período subsequente. Também não se verifica a participação de representantes do $\mathrm{CES}^{40}$.

\section{Conflito entre Estado e Municípios: a Gestão Competitiva (Maio de 1997 a Dezembro de 1998)}

\subsection{Alterações na Representação e no Processo Decisório}

Este período foi marcado pela intensa participação dos novos secretários municipais de saúde, oriundos dos governos municipais recém-eleitos e daqueles recém-emancipados; pela reeleição da Diretoria do COSEMS/RJ em março de 1997, proveniente da fusão das duas chapas concorrentes; pela participação ativa do Secretário Municipal do Rio de Janeiro nas reuniões da $\mathrm{CIB} / \mathrm{RJ}$ e por sua maior aproximação com o COSEMS/RJ; pela mudança do Secretário de Estado de Saúde em janeiro de 1998 (tendo assumido a secretaria a então Subsecretária de Planejamento e Desenvolvimento do Estado, Dra. Rosângela Bello) e pela irregularidade da participação do Ministério da Saúde.

As reuniões da $\mathrm{CIB} / \mathrm{RJ}$, neste período, também foram realizadas com um grande número de secretários municipais de saúde que participaram como observadores nas reuniões. A média de participação dos municípios nas 24 reuniōes realizadas no período foi significativamente maior que nos períodos anteriores (15 representantes/reunião), enquanto a participação do estado manteve-se constante (cinco representantes/reunião). Cabe ressaltar que, em 9 de setembro de 1997, é publicado o novo Regimento Interno da CIB/ RJ que amplia para cinco o número de membros efetivos da SES/RJ e do COSEM/RJ. A partir de 6 de fevereiro de 1998, é oficialmente ampliada a composição da CIB/RJ para o total de vinte membros efetivos e suplentes.

Destaca-se a presença de um representante do CES na reunião de janeiro de 1998. Embora neste dia, novamente tenha sido marcada a disposição da CIB/RJ em receber oficialmente um representante do CES em suas reuniões, tal medida não foi efetivada até o final de 1998. 
Quanto à participação federal, neste período, além do representante do ERERJ/MS esteve presente em mais de uma reunião um representante da Fundação Nacional de Saúde, devido às necessidades do tema abordado.

Embora a CIB/RJ tenha tido como característica expressiva no seu funcionamento a grande participação de secretários municipais de saúde, a partir do REFORSUS, muitos secretários começaram a estar presentes em todas as reuniões realizadas, entendendo este fórum como um espaço de negociação e decisão importante para a política de saúde não só do estado, mas de seu próprio município. Como o processo decisório da CIB/RJ foi caracterizado, em todo período analisado, pela negociação e tomada de decisão por consenso e não pelo voto, e como as reuniões sempre foram realizadas em caráter "aberto" à participação municipal, o direito à argumentação, com a presença maciça de secretários municipais de saúde, acabou por ampliar, na prática, a participação municipal e se tornar um importante mecanismo de fiscalização e pressão. Não por acaso, a eleição dos representantes do COSEMS/RJ na CIB/RJ passa a ser alvo de disputa acirrada entre seus membros.

Por outro lado, a mudança da Diretoria do COSEMS/RJ, com a alteração de seu Secretário Geral, acabou por modificar o modo de atuação da representação do COSEMS/RJ na CIB/RJ. A postura mais individualista adotada pelo novo Secretário Geral nas reuniões da CIB/RJ abriu espaço para uma fragmentação da representação municipal. O COSEMS/RJ, que até este momento, caracterizava-se por uma posição bastante coesa - apesar de internamente agregar representantes de visões, realidades e origens políticopartidárias distintas - sem abertura para negociações paralelas entre estado e municípios, passou a apresentar divergências em seus posicionamentos externos.

A mudança do Secretário de Estado de Saúde, por sua vez, marcou o início de um período de completo afastamento do Secretário das reuniões da CIB/RJ. No entanto, sua posição esteve presente no conjunto de dirigentes da SES/RJ ali representados. Cabe enfatizar que a ausência do Secretário impediu ou adiou a discussão e decisão de vários assuntos. Esta situação se diferencia daquela ocorrida em períodos anteriores, em que o afastamento do Secretário de Estado de Saúde das reuniões foi sobrepujado pela própria atuação dos dirigentes e técnicos de primeiro e segundo escalão da SES/RJ.

Nesta fase, tanto no plano financeiro, quanto no plano político, os conflitos caracterizaram-se pela constante suspeita, por parte dos municípios, de manipulação e favorecimentos pelo estado para elaboração dos tetos 
municipais, além das freqüentes denúncias referentes a medidas tomadas unilateralmente pela SES/RJ.

Tais conflitos ficaram mais explícitos nas discussões sobre a medida estadual para estipular um teto financeiro para a assistência hospitalar, e no julgamento do processo, encaminhado pelo município do Rio a CIB/RJ, solicitando a habilitação plena do sistema municipal.

É importante frisar que, neste último período analisado, apesar dos intensos conflitos, algumas questões e propostas importantes foram discutidas e encaminhadas pela CIB/RJ, fruto da negociação e do consenso entre estado e municípios. Entre elas, destaca-se a elaboração da Programação Pactuada e Integrada (PPI) e a aprovação dos pleitos de habilitação municipal às condições de gestão plena da atenção básica e do sistema municipal de saúde.

\subsection{Definição dos Tetos Financeiros Hospitalares e Elaboração da PPI}

A elaboração pela SES/RJ de uma proposta para a fixação de tetos financeiros para a assistência hospitalar foi feita com a justificativa do crescente aumento no valor médio das AIH, observado a partir de junho de 1997 e da constante extrapolação do teto financeiro global destinado ao estado.

Até então, o estado vinha fazendo ajustes financeiros na produção ambulatorial apresentada pelos municípios não habilitados ou habilitados em gestão incipiente e parcial do sistema, a partir do remanejamento dos recursos orçados a partir do sistema de informações e não faturados pelos municípios. Estes ajustes eram, na maioria das vezes, suficientes para equilibrar o faturamento do estado, não comprometendo seriamente os recursos repassados ou transferidos do nível federal para os municípios.

No entanto, alguns fatores agravaram a situação financeira do estado, não sendo mais possível a não realização de "cortes" na produção ambulatorial e hospitalar informada pelos municípios. Entre estes fatores destacam-se:

- Aumento progressivo da produção apresentada pela maioria dos municípios, principalmente devido ao aumento da capacidade instalada e, conseqüentemente, da capacidade de produção de serviços;

- Elevação dos recursos destinados à terapia renal substitutiva e à Diálise Peritonal Ambulatorial Contínua (ou CAPD), pela crescente entrada de pacientes renais cadastrados no sistema Autorização de Procedimentos de Alto Custo $(\mathrm{APAC})^{41}$; 
- Aumento do teto financeiro do município de Nova Iguaçu, devido à incorporação dos recursos da parcela ambulatorial especializada e da alta complexidade (FAE/ALTA), não passível de faturamento pelos municípios da Baixada Fluminense devido à ausência de capacidade instalada na região e destinados à Nova Iguaçu pela FRI ${ }^{42}$;

- Vigência do mesmo teto fínanceiro para o estado do RJ, congelado desde 1995;

- Impossibilidade do estado de reprogramar a utilização dos recursos não faturados (a "sobra" de teto) para pagamento de serviços no estado.

Frente a esta situação, a SES/RJ adota, em dezembro de 1997, a medida de fixar tetos para a assistência hospitalar, por intermédio de Ofício SES/RJ $\mathrm{n}^{0}$ 63, nunca antes discutidos pela CT ou CIB/RJ. Até o momento, a assistência hospitalar não possuía tetos financeiros, mas sim cotas de AIH (ou tetos físicos) a serem distribuídas nos diversos municípios. Foram feitos estudos da série histórica da produção hospitalar nos diversos municípios e encaminhados ofícios com a apresentação dos valores dos tetos estipulados para os municípios com capacidade instalada hospitalar.

Por parte do estado, a principal razão para fixação dos tetos financeiros hospitalares, além da necessidade do "ajuste das contas do estado", estava relacionada à urgência de implantação de uma medida, que não poderia aguardar os resultados das negociações políticas e do processo decisório da CIB/RJ.

A maior parte das críticas formuladas pelos municípios na época, contra a medida do estado, estavam relacionadas a não discussão da proposta pela $\mathrm{CT}$ e CIB/RJ antes da sua apresentação aos municípios. Nas reuniões da CIB/RJ, o assunto do teto financeiro hospitalar acabou, em sua maioria, saindo como informe, não merecendo o mesmo destaque recebido pela discussão do teto financeiro ambulatorial. A medida acabou sendo implementada sem a homologação da CIB/RJ a partir do início de 1998.

A urgência da revisão do teto financeiro global estadual e municipais, frente as intensas insatisfações e reivindicações por parte dos municípios, fez com que, em abril de 1998, por deliberação da CIB/RJ, fosse constituída uma Comissão com o objetivo de elaborar uma proposta para implementação da PPI no estado em curto prazo. A Comissão PPI, coordenada pelo CPS/ SPD/SES/RJ e composta por três representantes da SES/RJ e três representantes do COSEMS/RJ (o representante do MS nunca participou), reuniu-se periodicamente no período de majo a dezembro de 1998, respeitando 
razoavelmente o calendário de reuniões quinzenais. Além das reuniões periódicas da Comissão, foram realizadas duas oficinas de trabalho, a primeira em 18/06/98 e a segunda em 06/08/98, com a participação de técnicos oriundos das diversas regiões do estado para discussão, encaminhamento e implementação das propostas desenvolvidas. As atividades operacionais da Comissão foram conduzidas e executadas por um grupo técnico formado no $C P S / S P D^{4.3}$.

Os objetivos específicos da Comissão, segundo o Documento "Proposta de Atuação da Comissão PPI de maio de 1998 e março de 1998" (CPS/ SPD/SES/RJ, 1998) eram: formular proposta técnica de parâmetros físicos de necessidades de atenção em saúde; elaborar proposta metodológica de distribuição de recursos entre os municípios, considerando critérios de população, capacidade instalada, características regionais e processos de negociações entre gestores; propor mecanismos e instrumentos gerenciais que viabilizassem a pactuação entre gestores municipais e a avaliação do cumprimento das metas acordadas no processo de programação; elaborar proposta de revisão do teto financeiro global do estado de acordo com as necessidades de atenção à saúde; elaborar proposta de revisão dos tetos financeiros dos municípios de acordo com as necessidades de atenção à saúde e critérios utilizados na PPI.

Em virtude da informação da SAS/MS de que não haveria, em hipótese alguma, novo aumento de teto financeiro nos estados, fora aqueles já ocorridos no ano de $1998^{44}$ e frente à necessidade de elaboração de uma proposta de revisão dos tetos financeiros em curto prazo, a Comissão adota uma estratégia mais pragmática, formulando uma proposta que não rompeu com a lógica da programação vigente, ou seja, permaneceu utilizando três variáveis principais para definição dos tetos ambulatoriais municipais: a população, o perfil da capacidade instalada e os parâmetros de utilização de serviços. A inovação se deu pela valorização da pactuação entre gestores para o estabelecimento das referências intermunicipais.

A proposta da Comissão envolveu duas frentes de trabalho. Primeiro, o estabelecimento de novo teto orçamentário para o estado, no que se refere à sua fração ambulatorial, a partir de parâmetros de necessidades de utilização de serviços (estimativa do teto estadual "ideal"). Segundo, a proposição de nova distribuição financeira ambulatorial aos municípios, trabalhando com o teto do estado existente, através de nova metodologia para distribuição dos recursos entre os municípios. 
Com relação ao primeiro item, a Comissão fez uma revisão dos parâmetros em vigor na SES/RJ desde 1995 para a programação da parcela ambulatorial dos tetos financeiros municipais, através da comparação destes parâmetros com a série histórica de produção do estado (período de julho de 1994 a dezembro de 1997), com parâmetros utilizados em outros estados, com a produção de outros estados em 1997 e com os parâmetros de utilização de alguns tipos de serviços de apoio diagnóstico e terapêtico, fornecidos por consultor à SES/RJ.

Esta comparação permitiu a identificação de sete itens de programação, constantes da tabela SIA-SUS, considerados críticos para a revisão: AVEIANM, consulta médica, atendimento odontológico, patologia clínica, diálise, outros exames especializados e outras terapias especializadas. A partir dos novos parâmetros de utilização de serviços, além da inclusão de recurso para o item referente a medicamentos e da população estimada para 1998, foi calculado o "teto ideal" mensal, necessário para o estado em 1999. A diferença entre o teto estadual mensal no sub-total SIA, vigente em 1998 $(\mathrm{R} \$ 38.813 .853,69)$ e o teto ideal calculado $(\mathrm{R} \$ 57.098 .156,52)$ foi de $\mathrm{R} \$ 18.284 .302,83$.

Com relação ao segundo item, a proposta de revisão dos tetos ambulatoriais municipais, apresentada pela Comissão PPI, envolveu as realocações financeiras intermunicipais através da elaboração de um instrumento de pactuação intergestores - a Ficha de Programação Pactuada e Integrada (FPPI) - visando fortalecer compromissos entre gestores e permitir maior integração entre os serviços. Esta ficha, de formato e conteúdo semelhante à FRI, explicitava os recursos do teto ambulatorial a serem transferidos entre os municípios para a realização de procedimentos de média e alta complexidade.

Os tetos financeiros municipais foram revistos posteriormente ao estabelecimento dos acordos entre os gestores municipais expressos na FPPI, respeitando-se os pactos das referências dos procedimentos que os municípios não realizavam, substituindo-se o método anterior de rateio automático de recursos para os municípios-pólo (metodologia da "migração automática"). Além disso, a visibilidade do recurso transferido, em relação a sua origem, destino, valor e objetivo assistencial permitiu um maior controle por parte dos municípios que referenciavam recursos, fortalecendo seu poder de cobrança com relação à execução dos procedimentos referenciados nos municípios-pólo. 
No período de outubro a novembro de 1998 foram realizadas reunióes regionais, com e sem a participação da Comissão PPI, onde foram formalizados os acordos das referências, intra e extra-regionais, mediante o preenchimento das FPPI. Embora lento, o processo de negociação foi mais fácil nas regiōes em que a articulação-integração entre os municípios encontrava-se mais avançada. Durante a pactuação, estimulou-se a criação de fóruns regionais de negociação permanente, como forma de fortalecer este processo.

As FPPI, enviadas pelos municípios, foram digitadas em um sistema específico desenvolvido pelo CISA/SPD/SES/RJ, possibilitando a emissão de relatórios e análises acerca das referências intermunicipais. Os valores dos procedimentos referenciados passaram a constituir a parcela "Referências" nos novos tetos financeiros municipais.

Considerando que não houve aumento de teto financeiro estadual, o cálculo dos tetos financeiros ambulatoriais dos municípios seguiu várias etapas.

1. Definição da população de 1998 para cada município a partir da proporção de sua população no total do estado para o mesmo ano, aplicada à população total do estado em 1995;

2. Multiplicação desta população com os parâmetros de programação que vinham sendo utilizados desde 1995, gerando uma programação físicoorçamentária para cada município;

3. Quando existia a capacidade instalada no município, o recurso referente foi alocado diretamente como uma parcela do teto financeiro municipal. Quando não existia a capacidade instalada, três situações ocorreram:

- Procedimentos FAE Básicos, constituídos por procedimentos que, em princípio, todos os municípios deveriam fazer (nível de resolutividade considerado mínimo): o recurso foi alocado automaticamente no teto do município;

- Fração Ambulatorial Especializada - FAE (média complexidade): o município pôde alocar até $30 \%$ dos recursos referentes a estes procedimentos diretamente no seu teto financeiro, dependendo da vontade e manifestação do gestor neste sentido.

- Alta complexidade e pelo menos 70\% da FAE: o gestor decidiu para qual município referenciar estes procedimentos, através de um pacto regional (ou extra-regional) entre os municípios expressos na FPPI;

4. Definição da parcela da Terapia Renal Substitutiva (TRS) e Diálise Peritonial Ambulatorial Contínua (CAPD) ${ }^{45}$, a partir da produção apresentada pelos municípios, no mês de outubro de 1998, ou seja, da existência e funcionamento de centros de terapia renal; 
5. Definição da parcela de Hemoterapia, cuja programação foi baseada em proposta do Hemo-Rio, adaptada pelo CPS/SPD/SES/RJ, considerando a hemo-rede e seu funcionamento.

Assim, os novos tetos ambulatoriais passaram a ser constituídos pelas seguintes parcelas: PAB; FAE/ALTA Parcial; Referências Intermunicipais; Procedimentos Hemoterápicos; TRS e CAPD.

É importante destacar que as parcelas delimitaram os recursos a serem faturados nos municípios segundo o conjunto de procedimentos a eles relacionados. Os recursos, assim fixados, não poderiam sofrer realocações interparcelas, o que acabou por privilegiar determinadas áreas da assistência de maior complexidade. A partir dos valores delimitados nas parcelas, os municípios deveriam então reformular as Fichas de Programação FísicoOrçamentária (FPO) de suas unidades, de modo a permitir o faturamento do total dos recursos previstos.

No compito geral, os tetos ambulatoriais, decorrentes da aplicação da metodologia mencionada, geraram um aumento de recursos a serem distribuídos para 57 municípios e diminuição para 34, em relação à programação anterior. Estes novos tetos foram discutidos em Assembléia do COSEMS/ RJ, realizada em janeiro de 1999 , já em nova gestão da SES/RJ. O conflito ocasionado pela perda de teto em alguns municípios resultou na necessidade de haver um período de adaptação, principalmente para os municípios que sofreram maiores perdas.

Assim, foi proposto um escalonamento das perdas e ganhos, que incidiram na parcela da média e alta complexidade não referenciada pelos municípios. O escalonamento foi implementado da seguinte forma: em fevereiro de 1999 , os municípios cujos tetos foram aumentados, receberam somente $50 \%$ do valor do aumento previsto, ao passo que os municípios que incorreram em perdas superiores a $15,9 \%$ tiveram suas perdas amortecidas em $45 \%, 50 \%$ e $65 \%$, conforme o percentual de perda; em março de 1999, os municípios com aumento de teto receberam apenas $75 \%$ deste aumento e os municípios com perdas superiores a $15,9 \%$ tiveram suas perdas amortecidas em $25 \%$, $30 \%$ e $55 \%$, conforme o percentual de perda. Este escalonamento, proposto para fevereiro e março, foi aprovado na CIB/RJ. Portanto, os novos tetos começaram a vigorar na sua íntegra somente a partir de abril de 1999.

A CIB/RJ,na época, aprovou ainda um cronograma para a revisão das referências intermunicipais segundo nova repactuação a ser feita após três meses de vigência da primeira. Desta maneira, os tetos financeiros 
municipais seriam alterados periodicamente, de acordo com as alterações do perfil da capacidade instalada municipal e com as sucessivas pactuações intermunicipais.

Cabe destacar o intenso trabalho da Comissão PPI em formular uma proposta de construção de instrumento de pactuação entre gestores e de alocação de recursos entre municípios, de forma transparente e negociada. Durante o período de funcionamento da Comissão PPI em 1998, procurou-se dar visibilidade ao processo de construção da metodologia para realocação dos recursos entre os municípios através da elaboração e divulgação de uma série informações, documentos e relatórios de trabalhos e da realização de duas reuniões com técnicos representantes das distintas regiões do estado. Esta estratégia possibilitou a aderência dos secretários municipais de saúde à proposta formulada.

Um segundo fator, não menos importante para a implementação da proposta, foi a realização do trabalho por um grupo técnico da SES/RJ em conjunto com o COSEMS/RJ. Apesar de coordenar e executar o trabalho de formulação e operação da proposta, a SES/RJ contou com o apoio do COSEMS/RJ para a formulação da nova metodologia, discussão e divulgação da proposta entre os municípios. A FRI, embora tenha sido discutida e formulada com o apoio do COSEMS/RJ, não foi gestada no interior de uma Comissão paritária, constituída fundamentalmente com o objetivo de revisar os tetos financeiros municipais.

O terceiro fator refere-se à proximidade das eleições para o governo do estado e às expectativas com relação à mudança na gestão da SES/RJ. A perspectiva da posse de um novo Secretário de Estado de Saúde oriundo de uma secretaria municipal de saúde do RJ aumentou a urgência da elaboração e aprovação de uma nova proposta de revisão dos tetos municipais ${ }^{46}$.

Estes três fatores, mais a transparência absoluta do processo, a realização de um trabalho conjunto entre estado e municípios na Comissão PPI e expectativa de mudança da gestão da SES/RJ foram fundamentais para o êxito da FPPI e aceitação dos novos tetos pelos municípios, mesmo com conflitos.

\subsection{Habilitação do Município do Rio à Gestão Plena}

A discussão sobre o processo de habilitação do município do Rio de Janeiro, pela segunda vez encaminhada a CIB/RJ, agora na vigência da NOB SUS 01/96, teve início em fevereiro de 1998 e foi ponto de pauta de 
uma série de reuniões da CT e da CIB/RJ. Desta vez, o processo - com mais de mil páginas - foi apresentado sem pendências do ponto de vista jurídico-normativo. As divergências quanto a aprovação do processo se deram principalmente devido à exigência imposta pelo estado, do aumento dos recursos para pagamento dos serviços prestados pelas unidades estaduais localizadas no município do Rio e à gerência do sistema de média e alta complexidade no estado.

A proposta de teto apresentada pelo município do Rio foi a de manter aquele já destinado para o município desde 1995. A proposta do estado foi inicialmente a de solicitar sete milhões do teto do Rio, a serem destinados ao Fundo Estadual de Saúde para pagamento dos serviços prestados nas unidades estaduais situadas no município. Este valor, apontado como sendo bem superior à média do valor da produção apresentada pelas unidades estaduais até então, foi questionado e negado pelo Secretário Municipal de Saúde do Rio. A argumentação sustentada pelo estado era a de que estaria se garantindo recursos financeiros para a eventual otimização da capacidade produtiva dos hospitais estaduais, alcançada com o processo de terceirização de sua gerência através do Programa de Hospitais em Locais Populares $\left(\right.$ HELP) ${ }^{47}$.

As tentativas de negociação e formação de acordos que se seguiram, envolveram a assinatura de um termo de compromisso pelo município do Rio, assegurando a transferência do valor estipulado pelo estado. Este termo de compromisso não foi levado adiante devido à impossibilidade de negociação com relação ao valor pleiteado pelo estado.

A impossibilidade de acordo entre estado e municípios se agravou com a posição apresentada pelo Secretário Geral do COSEMS/RJ, Dr. Marco Aurélio Couto Silva, Secretário Municipal de Saúde de Itaguaí, que, apoiado por documento assinado pelos municípios da Região da Baixada Fluminense, foi contrário à habilitação do município do Rio devido a falta de garantia de atendimento das suas referências. A posição do Secretário de Itaguaí, diferentemente da posição expressa pelo COSEMS/RJ, levou a uma divergência clara entre os membros do COSEMS/RJ, expressa durante a reunião da CIB/RJ. As divergências internas do COSEMS/RJ até então, fruto de posicionamentos diferentes, quer seja no plano político-partidário, quer seja no plano de interesses particulares ou corporativos, vinham sendo resolvidas em reuniões prévias de Diretoria ou entre os seus representantes para retirada de uma única posição a ser levada para CIB/RJ. Este fato criou uma 
abertura para a realização de negociação e de acordo político entre estado e municípios à margem das negociações com o COSEMS/RJ.

A situação de impasse criado fez com que o Secretário Municipal de Saúde do Rio solicitasse a votação do processo pelos membros da CIB/RJ, o que não ocorreu. O presidente do COSEMS/RJ, Dr. Luiz Antônio da Silva Neves (SMS de Piraí), frente à situação desfavorável, decorrente da falta de coesão entre os seus membros, utilizando-se do argumento da CIB/RJ sempre adotar nos processos decisórios a prática da negociação e decisão por consenso entre seus membros, impedindo a votação.

O processo foi então encaminhado a CIT para apreciação. Pela primeira vez, na história da CIB/RJ, foram testados recursos deliberativos previstos para situações de impasse em suas negociações. A CIT, considerando a possibilidade de acordo entre estado e município, deliberou uma Comissão para acompanhar de perto o processo na $\mathrm{CIB} / \mathrm{RJ}$. Este retorna para a $\mathrm{CIB} /$ RJ e o estado é convocado para apresentação de uma proposta por escrito, onde sugere a manutenção do gerenciamento dos procedimentos de média e alta complexidade pelo estado ${ }^{48}$, a revisão da programação físico-orçamentária das unidades estaduais, visando garantir recursos para o Programa HELP e a necessidade de novos recursos para o custeio das unidades federais municipalizadas. Na proposta, o estado condiciona a habilitação do município à gestão plena da atenção básica e não à gestão plena do sistema municipal, ao cumprimento dessas exigências em prazo de noventa dias.

Mesmo a intermediação do nível federal que, com uma postura menos intervencionista e mais apaziguadora, tentou detalhar todos os pontos de conflito no processo - o sistema de referência de alto custo, a municipalização das unidades federais e o recurso para as unidades estaduais - não foi suficiente para a celebração de um acordo. A discussão foi encerrada, neste momento, com a retirada do processo pelo município do Rio.

O processo de habilitação do Rio à gestão plena do sistema só foi aprovado no final de 1998, fim do governo Marcelo Alencar, sem a resolução dos conflitos aqui apontados e impedindo a continuidade da negociação de questões relevantes para a relação estado-capital ${ }^{49}$.

$\mathrm{Na}$ aprovação dos processos de habilitação dos municípios do estado do Rio às condições de gestão da NOB SUS 01/96, de forma geral, é preciso enfatizar os esforços, tanto da CT, quanto da CIB/RJ, para a implantação de alguma condição de gestão em todos os municípios do estado até o final de 1998. No final do período, 73 municípios foram habilitados no modelo de atenção básica e 18 no modelo de atenção plena do sistema de saúde, 
aumentando em onze o número de municípios a receber a transferência global dos recursos assistenciais "fundo a fundo" 50 . No entanto, o processo de avaliação dos pleitos de habilitação seguiu, ainda nesta fase, formato bastante cartorial, não sendo possível a elaboração de uma proposta de avaliação, aprovação e acompanhamento do desempenho dos municípios nos modelos de habilitação, gestada no âmbito do estado ou da própria CIB/RJ.

Acrescenta-se, no período, como rotina para avaliação da CT e deliberação na CIB/RJ os processos municipais solicitando recursos do Plano de Combate às Carências Nutricionais e do PACS/PSF a serem transferidos "extrateto". Incentivos financeiros previstos na NOB SUS 01/96.

No que se refere ao novo Regimento Interno da CIB/RJ, este reflete um amadurecimento das discussões travadas na CIB/RJ. A avaliação regular da permanência dos municípios habilitados nas condições de gestão da NOB SUS em vigor passa a ser uma das suas principais atribuições. No entanto, não se observa até o final de 1998 o desenvolvimento de instrumentos e mecanismos para este acompanhamento. Na prática, o Regimento nada mais é do que uma consolidação, por escrito, das rotinas, fluxos e processo decisório da CT e CIB/RJ, mal estabelecidas na resolução da SES/RJ que cria a CIB/RJ. Seu efeito mais imediato foi a ampliação dos membros da CIB/RJ, como discutido anteriormente.

Quanto à intervenção em Nova Friburgo - município na época em gestão semiplena -, esta foi feita através de constituição de uma Comissão paritária formada por membros da SES/RJ e COSEMS/RJ para junto à Secretaria Municipal de Saúde de Nova Friburgo, acompanhar a negociação dos débitos com os prestadores do SUS no município e o trabalho de assessoramento da SES/RJ no SIA e SIH-SUS. É interessante notar que o processo denunciando as irregularidades no repasse foi encaminhado à $\mathrm{CIB} / \mathrm{RJ}$ através da representação do próprio CMS de Nova Friburgo ${ }^{51}$. Apesar da constatação de irregularidades no repasse dos recursos federais aos prestadores coníratados, o processo não resultou na desabilitação do município à condição de gestão. Muito pelo contrário, no final de 1998, este município é habilitado na condição de gestão plena do sistema municipal segundo à NOB SUS 01/96.

\section{Discussão}

É certo que as CIB cumprem papel fundamental para a operacionalização das NOB SUS 01/93 e 01/96, assim como foram consideradas estratégicas para o reforço da capacidade gestora do SUS e organização da gestão da 
assistência à saúde nos encontros patrocinados pela SAS/MS em 1995 e para a seleção dos projetos a serem contemplados com recursos do REFORSUS. No entanto, cabe ressaltar que a CIB/RJ não avançou na discussão dos elementos próprios, constitutivos do sistema estadual do Rio de Janeiro, adaptando diretrizes e estratégias nacionais à realidade locoregional, não se constituindo como fórum de formulação da política estadual e planejamento de ações. Pelo contrário, consolidou-se fundamentalmente como um espaço de execução e operacionalização das diretrizes nacionais da política de saúde.

Observa-se ainda, uma forte influência dos períodos eleitorais para o andamento e resultados das discussões travadas.na CIB/RJ. Tais períodos acentuam os conflitos e são motivadores de disputas entre estado e municípios na condução do processo decisório, demonstrando a permeabilidade deste fórum às influências do sistema político.

No que se refere à representação, é marcante a crescente participação dos secretários municipais de saúde e técnicos das respectivas secretarias nas reuniões da $\mathrm{CIB} / \mathrm{RJ}$. A CIB/RJ torna-se, para os municípios, cada vez mais, a garantia de informação e atualização dos instrumentos técnicooperativos da política de saúde, de implementação dos avanços na descentralização do sistema de saúde, de fiscalização das ações do estado na defesa de seus interesses principalmente com relação à distribuição dos recursos repassados ou transferidos pelo nivel federal.

Apesar das propostas de realocação dos recursos ambulatoriais entre os municípios com base na PPI (FRI e FPPI) e de distribuição dos próprios recursos do REFORSUS terem incentivado a discussão sobre aspectos da regionalização do sistema de saúde, não se verificou, no período, a consolidação de uma rede de assistência integral e de referência intermunicipal no estado. Permanecem os conflitos com relação à disputa dos recursos financeiros informados pela ótica do município isoladamente e não das necessidades da região, sem a criação de instrumentos que possam garantir o atendimento da referência nos municípios-pólo. A regionalização, portanto, ainda aparece como uma discussão marginal a CIB/RJ, não sendo foco de discussão específica e direta ${ }^{52}$. Somente a programação financeira integrada dos recursos federais do SUS não é suficiente para a integração e regionalização do sistema de saúde.

Para o estado, a CIB/RJ aparece como uma instância por vezes benéfica para a implementação de medidas, devido à possibilidade de negociação, aprovação e aceite dos municípios. Por outro lado, diminui a agilidade na 
execução de propostas por exigir um longo processo de discussão e pactuação. Isto pode explicar as diversas posturas e a irregularidade da participação dos Secretários de Estado de Saúde na CIB/RJ, durante o período analisado e as diferentes tentativas de condução do processo decisório pela SES/RJ, seja por ação direta de seus membros, seja por omissão do próprio Secretário. No entanto, destaca-se a importância do estado para as discussões, não só pelas atividades técnicas desenvolvidas pelo seu corpo de dirigentes e funcionários (produção de informações e análises, avaliação e instrução de processos, etc.), como também pela própria natureza dos problemas envolvidos. Muitas vezes, a disputa por recursos financeiros e as dificuldades de entendimento entre os próprios municípios exige uma intervenção mais eqüalizadora da instância estadual.

Embora tenha sido uma deliberação da própria CIB/RJ, a presença de um representante do MS visando propiciar uma maior integração entre o conjunto de serviços de saúde federal existente no município do Rio e o sistema de saúde estadual, não se observa, no período, uma efetiva integração desses serviços. Apesar do representante federal desempenhar papel fundamental para informação e discussão sobre os aspectos específicos de sua rede de serviços, nunca se conseguiu discutir claramente o orçamento de suas unidades, as funções a serem desempenhadas para o sistema estadual como um todo e a efetiva incorporação dos valores de sua produção no teto financeiro estadual. Este último aspecto foi sempre um motivo de conflito, evidenciado principalmente nos momentos de solicitação da habilitação à condição de gestão semiplena e plena pelo município do Rio. Na visão do estado, o município do Rio encontra-se em posição financeira mais favorável ao contar com o recurso "extra-teto" das unidades federais ${ }^{53}$. Porém, mesmo para o município, a discussão sobre a municipalização das unidades federais e da sua integração com a rede municipal sempre foi problemática, principalmente no que tange aos recursos financeiros envolvidos.

A representação do CES foi aprovada pela CIB/RJ ainda em 1995, embora não formalizada através de deliberação específica. Contudo, não se verifica uma maior aproximação entre o CES e a CIB/RJ, quer seja através da participação regular de seu representante nas reuniões da CIB/RJ ou CT, quer seja através da homologação final de deliberações da CIB/RJ. Os processos de credenciamento/cadastramento de serviços e habilitação municipal, assim como os tetos financeiros municipais, aprovados até o final de 1998, não foram sequer analisados pelo CES. No entanto, todos receberam parecer favorável após julgamento da CIT. 
Com relação as pautas, as questões ligadas à assistência com relação à habilitação municipal e delimitação dos tetos financeiros permanecem como pontos mais freqüentes, agregando um maior número de participantes e gerando maiores polêmicas e conflitos. Chama atenção no período, a ausência de discussões acerca de programas e projetos estaduais e da alocação de recursos próprios do estado nos municípios. A CIB/RJ não parece competir com a instância estadual nos aspectos referentes à sua política própria, muito embora, como já analisado, atue cerceando as funções estaduais no que diz respeito à execução das diretrizes nacionais. O estado, no entanto, segue atuando com forte poder coordenador nas discussões travadas na CIB/RJ.

As freqüentes disputas evidenciadas entre a SES/RJ e o COSEMS/RJ na condução do processo decisório da CIB/RJ não parece diminuir a importância da pactuação.

Devido à dinâmica de negociação e deliberação por consenso estabelecida na CIB/RJ e ao conteúdo dos temas abordados, muitos assuntos foram aprovados após longo processo de discussão, envolvendo um grande número de reuniões da CT e extraordinárias da própria CIB/RJ. O processo decisório não foi exercido em momento algum sob o voto (mesmo nos momentos de maiores dificuldades de formação de acordos políticos) e o direito à voz nas reuniões abertas da $\mathrm{CIB} / \mathrm{RJ}$ acabou por ampliar de fato a participação municipal. Esta participação, no entanto, se deu, na maior parte do tempo, coordenada pelo COSEMS/RJ, o que aumentou sua função de articulação e mediação de conflitos intermunicipais e entre estado e municípios. Também é marcante a influência da CT nas decisões da CIB/RJ, possibilitando muitas vezes a diminuição de conflitos políticos ao transferi-los para um espaço de discussão mais técnico-operacional.

As características acima apontadas, referentes ao processo decisório, parecem ter consolidado a CIB/RJ como um espaço de deliberação equilibrado, democrático e participativo entre eștado e municípios.

Por fim, destaca-se a permanência dòs mesmos conflitos durante o processo de negociação na CIB/RJ, em todas as fases analisadas, sejam elas caracterizadas por maior cooperação ou maior competição entre estado e municípios. Alguns destes tornam-se, em alguns momentos, mais expressivos, motivados por fatores externos ou internos à organização. Em especial, as disputas pela distribuição dos recursos federais, como pauta principal da $\mathrm{CIB} / \mathrm{RJ}$, são as principais fontes de conflito, sejam entre os municípios ou entre estado e municípios. No entanto, nem as modificações nas diretrizes 
nacionais, nem as alterações observadas na organização interna, no processo decisório da CIB/RJ e no relacionamento entre as instâncias subnacionais de governo são capazes de solucioná-los. Os problemas geradores de conflito são, principalmente, de ordem estrutural ao campo das relações intergovernamentais, da política nacional de saúde e do próprio sistema estadual do RJ, não resolvidos através da implantação da $\mathrm{CIB} / \mathrm{RJ}$ ou das sucessivas NOB do SUS.

\section{Considerações Finais}

Afinal, como podemos avaliar a importância das CIB na política de saúde? A evolução da política de saúde na década de 90 (tendo como base as Normas Operacionais Básicas do SUS) e a análise do funcionamento da CIB/RJ demonstram que estas instâncias têm desempenhado papel fundamental na operacionalização das diretrizes nacionais e na descentralização do sistema de saúde. Há claramente um avanço no modelo de descentralização adotado pela política de saúde em direção à municipalização da gestão (incluindo recursos e instrumentos), à explicitação das funções estaduais enquanto coordenadores do sistema de referência intermunicipal e ao reforço do nível federal enquanto regulador e indutor do processo de descentralização em curso. Como reflete Labra (1999), o fato dos procedimentos de decisão das CIB estarem informados e apoiados pelas normas nacionais, por si só garante legitimidade a estes fóruns.

A autora sugere que a multiplicação das formas de representação na política de saúde (CIB, CIT, Conselhos de Saúde, Conselhos de Representação de Gestores) tem como conseqüência mais imediata o "adensamento quantitativo e a dispersão territorial do associativismo setorial". Por outro lado, as Comissões Intergestores se configuram como novos estilos de fazer política. Situando-se enquanto importantes centros de decisão da política de saúde, estas instâncias rompem com antigas formas de representação "corporativas estáveis" da saúde e não parecem apontar para novos "formatos pluralistas", mas sim, para uma rede de políticas e de poder cada vez mais especializada e restrita.

O estudo apresentado parece comprovar tais afirmações. Apesar de não ser um fórum "fechado", na CIB/RJ atuam quadros qualificados tecnicamente e referendados politicamente, seja pelo órgão estadual de representação dos secretários municipais de saúde (COSEMS), seja pelas próprias secretarias de saúde (municipais e estadual), sejam pelos governos locais. 
A pouca integração com o CES, por sua vez, circunscreve o espaço deliberativo da política, com pouca abertura para o controle social.

No entanto, cabe enfatizar que o mérito da execução da política através de instâncias colegiadas de gestão está na possibilidade da construção da parceria do estado com municípios e na consolidação de uma prática de negociação entre os gestores locais da política mais equilibrada, democrática e participativa.

Não se espera através desta instância, superar todos os conflitos intergovernamentais presentes na política de saúde. Espera-se, porém, assegurar o princípio da interdependência entre os gestores do sistema de saúde através de um processo de negociação permanente entre as instâncias de governo e de busca da cooperação, num jogo contínuo e recorrente de competição-cooperativa, formas e mecanismos para superação dos conflitos.

A experiência do processo decisório na CIB/RJ mostra que mesmo nos períodos de grande tensão no sistema político-eleitoral (mudanças de governo, de gestores, da direção do COSEMS) é possível formar pactos e firmar acordos políticos que apontem para soluções de problemas. Esta afirmativa pode ser claramente identificada em diferentes momentos da CIB/RJ. Em especial, no último período analisado, mesmo frente à escassez e insuficiência de recursos federais a serem distribuídos nos municípios e a uma conjuntura política desfavorável, conseguiu se aprovar uma metodologia de pactuação e rateio dos tetos financeiros ambulatoriais, onde municípios semiplenos ou plenos do sistema, nem todos municípios-pólo com grande capacidade instalada, realocaram recursos antes transferidos diretamente para o Fundo Municipal de Saúde.

O debate exaustivo sobre alguns assuntos, por outro lado, exige uma qualificação e atualização cada vez maior dos gestores sobre os aspectos e instrumentos político-operacionais da política de saúde, já que é o argumento é principal arma de convencimento para obtenção do consenso e aprovação de medidas. A discussão também ajuda a polemizar algumas dificuldades encontradas em diferentes níveis do sistema, sejam elas entendidas como sendo tipicamente da alçada municipal (executora de ações e serviços) ou estadual (coordenadora e planejadora). Assim, os problemas são coletivizados, rompendo com algumas práticas tradicionalmente clientelísticas (de soluções unilaterais e de troca de favores) em busca de critérios técnicos e soluções mais homogeinizadoras e, até certo ponto, eqüalizadoras na distribuição de recursos federais entre os municípios. 
Se os benefícios são muitos, as limitaçōes ainda sāo grandes. Uma delas, evidenciada no estudo do Rio, diz respeito à ausência de discussão e formulação coletiva para o enfrentarnento dos problemas regionais. Uma das razões para tal fato está no "aprisionamento" da política federal. Se o grande argumento da descentralizaçäo fala a favor da proximidade das demandas, do maior controle social e, conseqüentemente, maior eficiência das políticas, resta saber se o fato das instâncias subnacionais e suas estruturas colegiadas de gestão ainda não conseguirem ser suficientemente autônomas para planejarem a apontarem para programas e projetos regionais, implicaria na perda de alguns dos benefícios preconizados através da descentralização.

Em que pese os avanços obtidos através das NOB 01/93 e 01/96 com a ampliação das transferências "fundo a fundo" e maior autonomia dos gastos dos recursos federais transferidos, a descentralização ainda permanece suficientemente "tutelada", agora através dos instrumentos da programaçāo, do controle e da avaliação. São tantos os requisitos a cumprir, tantos cálculos, regras e mecanismos de controle a serem respeitados e efetuados que o tempo e o espaço para se planejar e viabilizar políticas torna-se escasso.

Não se quer dizer que estes mecanismos não devam existir ou não devam ser aprimorados pela instância nacional. O que se quer questionar é se eles não foram excessivamente burocratizados e centralizados pelo nível federal. Dificilmente estas características permitiriam a "adaptação das normas nacionais reguladoras às condições específicas de cada estado" pelas CIB, como preconizado na NOB SUS 01/93.

Acrescenta-se ainda, que os recursos próprios do nível estadual, pelo menos no caso da CIB/RJ, não foram colocados à mesa para o debate e por isso mesmo, não estão sujeitos à gestão colegiada. Isto se deve em parte à carência de recursos desta instância, estrangulada por suas dívidas e pela "guerra fiscal".

Um dos ensinamentos que o processo de descentralização da política de saúde conduzido fortemente pela instância federal nos deixou é que, a distribuição de recursos financeiros entre os níveis subnacionais é um grande instrumento de regulação e coordenação da política de saúde. Sem recursos para distribuir fica difícil induzir mecanismos compensatórios e corrigir as distorções dos sistemas de saúde municipais. Os instrumentos da programação e realocação dos tetos financeiros não são suficientes para estes fins, pois estes estão, em última análise, amarrados à produçäo. No cntanto, também é certo afirmar que a instância estadual no RJ apresenton-se 
altamente resistente a debater com as instâncias municipais seu orçamento, programas, projetos e gasto na saúde.

Um outro ponto importante, a destacar no caso do Rio, é a dificuldade de integração da rede de serviços federais. É interessante observar que estas continuam a obedecer a uma lógica de financiamento e atuação à margem do sistema de saúde do município e do estado do Rio. A discussão é bastante complexa, pois a municipalização ou estadualização dessas unidades deve implicar na garantia dos recursos federais já transferidos para sua manutenção, sob pena da desativação de alguns serviços. $O$ fato é que este problema, que é estrutural do sistema de saúde do Rio, não apresenta solução no curto prazo, aumenta a concentração de recursos na capital e agrava as disputas político-financeiras entre o estado e o município do Rio.

As limitações acima apontadas não devem servir como justificativas para a falta de criatividade e a ausência de formulação política e planejamento no nível estadual. Afinal, as arenas de representação e decisão da política ampliaram as possibilidades da participação dos gestores na defesa de seus interesses e ajudam a legitimar novas diretrizes que, por ventura, sejam desenhadas nos diferentes níveis do sistema.

Finalmente, faz-se necessário situar a importância deste estudo de caso, ainda exploratório, para a confecção de uma agenda de investigações futuras. Várias questões e aspectos da política, levantados durante este trabalho, merecem ser mais bem apurados em estudos comparativos, que relativizem estes achados e permitam comprovar ou refutar algumas hipóteses.

Mesmo na ausência destes estudos, os elementos aqui apontados sugerem que as CIB são inovações salutares à política de saúde. Se ainda há muito por fazer, certamente os caminhos serão gestados em espaços coletivizados da política, garantidos por estas instâncias.

\section{Notas}

1 Médica sanitarista da Secretaria Municipal de Saúde do Rio de Janeiro; mestre em Saúde Coletiva pelo IMS/UERJ, na área de concentração Políticas, Planejamento e Administração em Saúde.

2 Fundado em 1988, através de uma reunião entre os secretários municipais de saúde em Araruama, quando foi eleita sua primeira Diretoria, teve os seguintes presidentes com mandatos bianuais: Sérgio Oeste (Secretário de Saúde de Teresópolis) de 1988 a 1990 , Gilson Cantarino O'Dwyer (Secretário de Saúde de Niterói) de 1991 a 1994 (reeleito em 1993) e Luiz Antônio da Silva Neves (Secretário de Saúde de Pirấ), de 1995 a 1998 (reeleito em 1997). Entre 94 e 96, o COSEMS/RJ foi presidido interinamente por 
Agostinho Seródio Boechat (Secretário de Saúde de Bom Jesus de Itabapoana) e por Walter Lavinas (Secretário de Saúde de Comendador Levy Gasparian) (COSEMS/RJ, 1997).

A estrutura organizacional do COSEMS/RJ contém oito Vice-Presidências Regionais, que correspondem as seguintes regiões do estado do RJ: Baía da llha Grande, Baixada Litorânea, Centro-Sul, Médio-Paraíba, Metropolitana, Noroeste, Norte e Serrana (COSEMS/RJ, 1997).

+ O representante do MS na CIB/RJ, na figura de observador sem direito a voto, é aprovada e incorporada formalmente à $\mathrm{CIB} / \mathrm{RJ}$ a partir da primeira reunião da $\mathrm{ClB} / \mathrm{RJ}$ em 1995 (12/01/95).

5 A participação da capital na CIB/RJ foi marcada pela atuação de seu suplente, Dr. Valmi Pessanha, de perfil técnico, na maior parte das reuniōes e também na CT.

- Na época uma série de escândalos envolvendo a SES/RJ foi amplamente divulgada e debatida pela imprensa (Parada, 1997).

7 Em julho de 1988, através do Decreto $\mathrm{n}^{2}$ 11.562/88 do Governador de Estado, a estrutura da SES/RJ foi reformulada para atender à incorporação das funções oriundas do INAMPS. Entre as várias alteraçōes no organograma da SES/RJ, destaca-se a extinção dos Órgãos de Representação da SES/RJ (ou Coordenadorias Regionais) nas diversas regióes do estado, para permitir uma efetiva delegação de poderes e conseqüente fortalecimento das secretarias municipais de saúde (Rio de Janeiro, Secretaria de Estado de Saúde, 1990).

8 Para uma discussão mais aprofundada deste período ver Revista Divalgação en Saúde para Debates, setembro de 1989; Rio de Janeiro, Secretaria de Estado de Saúde (1990); Levcovitz \& cols. (1990) e Azem \& cols. (1991).

9 Parada (1997) ao analisar a atuação da SES/RJ no período, destaca os seguintes problemas enfrentados: dificuldade de manutenção financeira dos hospitais federais estadualizados, devido a suspensão de repasses financeiros federais, com posterior recentralização dos mesmos; término do Programa Especial de Saúde da Baixada (PESB); grande evasão de profissionais de saúde e não concretização da construção dos Hospitais de Saracuruna e Queimados.

10 Os Secretários de Estado de Saúde, que atuaram na gestão do governador Leonel Brizola (1991/1994) foram: Pedro Gomes Valente (1991/1992), Luiz Cadorna (1992/1993) e Astor de Mello (1993/1994).

11 Destaca-se a adoção do modelo do médico de família pela Prefeitura Municipal de Niterói.

12 Também conhecida como Subsecretaria de Assuntos do Interior, esta estrutura criada através do Decreto 12816 de 03/04/89 (Rio de Janeiro, Secretaria de Estado de Saúde, 1990), exerceu papel fundamental para a condução estratégica da municipalização no período anterior (1987 a 1990).

13 É interessante observar que o nome do Secretário de Estado de Saúde nāo aparece na lista dos membros efetivos da SES/RJ, embora seja de sua responsabilidade a indicação dos representantes da SES/RJ e - como previsto no primeiro Regimento Interno da CIB/ RJ, publicado no ato de sua criação - a homologação de todas as decisões aprovadas na Comissão, função esta determinada ao Conselho de Estado de Saúde pela NOB SUS $01 / 93$. 
14 A Diretoria do COSEMS/RJ é composta por um Presidente, um Vice-Presidente, um Secretário Geral e um Tesoureiro. Posteriormente, em 1996, é criada a figura do Secretário Executivo com funçōes de assessoria técnica (COSEMS/RJ, 1997).

15 Na época, o Secretário Municipal de Saúde do RJ não fazia parte da Diretoria do COSEMS/RJ e não participava regularmente de suas reuniōes.

16 Esta composição se manteve até a ampliação dos membros da CIB/RJ com a edição do novo Regimento Interno, em setembro de 1997, que aumentou o número de membros efetivos e suplentes para 20 ( 10 oriundos dos municípios e 10 da SES/RJ).

17 Os membros do COSEMS/RJ na CT tinham e mantiveram em todo período de funcionamento da CIB/RJ analisado, um perfil majoritariamente técnico devido principalmente a própria característica de seus representantes, relacionada aos cargos e funções ocupadas nas secretarias municipais de saúde e no COSEMS/RJ.

18 Un dos representantes nomeados pela SES/RJ foi o próprio Subsecretário Adjunto da Municipalização: Dr. Walter Ramos Lopes.

19 No Rio de Janeiro, apesar do CES estar previsto em Lei Complementar à Constituição Estadual de janeiro de 1991, sua criação foi vetada pelo então governador de estado Leonel Brizola. A aprovação do texto consolidado da Legislação que disciplina o CES foi feita somente em 14 de maio de 1996 pelo governador Marcelo Alencar.

20) Termo este referido no texto do Plano Estadual de Saúde para 1995 a 1998 , em correspondência ao Programa de Satide da Familia (PSF).

21 Para comparação do "novo" organograma da SES/RJ com as mudanças implementadas em 1988/1989 consultar Levcovitz \& cols. (1990).

22 Ressalta-se em 1996 a criação do cargo de Secretário-Executivo no COSEMS/RJ, como um dos membros de sua Diretoria, com atribuições de coordenação da assessoria técnica.

23 O fluxo decisório passa a ser estabelecido a partir do parecer da CT sobre os processos a ela remetidos, enviado posteriormente à CIB para discussão, aprovação e deliberação.

Diferentemente do período anterior, a CT, neste momento, foi composta por membros do segundo escalão da SES/RJ (e não do primeiro escalão). Com relação ao COSEMS/ RJ manteve-se a participação de técnicos oriundos dos municípios ou do próprio
COSEMS/RJ.

25 Ressalta-se ainda, a participação de um representante do MS, oriundo do ERERJ/MS, como observador da CIB/RJ, com direito a voz e sem direito a voto, desde o início das reuniōes. Esta decisão foi acatada por todos os membros da CIB/RJ na primeira reanião realizada no período, devido ao número expressivo de serviços hospitalares federais existentes no município do RJ e da necessidade de integração destes serviços, com outros serviços de saúde no estado. A partir de então, um representante do ERERJ/MS passou a estar presente na maior parte das reuniões da CIB/RJ. Apesar da participação ativa do representante do MS, de suas contribuiçōes para o andamento das discussōes e informaçōes com relação aos projetos encaminhados pelo ERERJ/MS e o funcionamento dos serviços federais no município do RJ, permanecem as dificuldađes de integração com o sistema de saúde municipal e estadual.

26 Participaram da elaboração das propostas, técnicos do Centro de Informações em Saúde - CISA - e do CPS da SPD da SES/RJ. 
27 Os tetos fixados para os municípios que pleiteavam a gestão semiplena em 1994 foram calculados com base na série histórica de produção destes municípios. Com exceção de Petrópolis, habilitado em condição de gestão parcial do sistema através da deliberação n0 03 da CIB/RJ de 08 de outubro de 1996, todos os municípios habilitados à condição de gestão semiplena em 1994 tiveram seus tetos estipulados e assumiram a condição de gestão semiplena em 1995. Na época, o município de Petrópolis retrocedeu em sua decisão de pleitear a condição de gestão semiplena por discordar do teto financeiro estipulado.

Os tetos, portanto, dos municípios em semiplena foram revistos a partir da aprovação de novos critérios pela CIB/RJ em setembro de 1996.

A proposta da FRI (como era chamada a nova proposta) foi formulada basicamente por funcionários do segundo escalão da SPD da SES/RJ, respectivamente do CISA e do CPS.

30 No final do governo Marcelo a proposta da FRI foi reeditada com novo nome: FPPI (Ficha de Programação e Pactuação Integrada). Este aspecto será discutido mais adiante.

31 Outros pontos de pauta destacaram-se no período: formulação e aprovação do Plano de Investimentos do MS para o estado, com a definição das prioridades; intervenção estadual nos municípios de Santo Antônio de Pádua e Nova Iguaçu; Sistema Nacional e Estadual de Auditoria; política estadual de distribuição de medicamentos; gerenciamento do sistema de alto custo e alta complexidade; Programa de Saúde da Família (PSF); Normas para credenciamentos e cadastramento de unidades; Consórcios intermunicipais de saúde; Municipalização da vigilância e fiscalização sanitária; análise das propostas estadual e municipal para formulação da NOB SUS 01/96; Sistema estadual de sangue e hemoderivados; Plano Nacional de Combate ao Dengue; enquadramento do estado na gestão parcial; avaliação e julgamento dos pleitos de habilitação dos municípios às condições de gestão da NOB SUS 01/93, em especial, aprovação da condição de gestão semiplena para Nova Friburgo; análise da mortalidade materna no estado. Cada um destes pontos foi objeto de discussões específicas, com graus de aprofundamentos diferenciados. Porém, as polêmicas e divergências foram resolvidas no âmbito das reuniōes e todas as resoluções tomadas por consenso.

32 Este foi um dos principais problemas apontados pelos atores entrevistados na pesquisa. A alta rotatividade de secretários municipais de saúde prejudica o entendimento, o amadurecimento e a evolução das discussōes na CIB.

33 Vale destacar que, nesta reunião, não estava presente o Secretário de Estado de Saúde, que teve sua ausência justificada por um encontro marcado com o governador Marcelo Alencar. A ausência do Secretário de Estado de Saúde foi um dos argumentos levantados pelo estado para o adiamento da discussão e aprovação do processo, já que alguns acordos só poderiam ser feitos com a presença do Secretário.

34 Estes argumentos centravam-se na discussão acerca da singularidade da rede pública de serviços de saúde existente no Rio, no conseqüente avanço para o processo de descentralização da política de saúde no estado e na ressonância política nacional provocada com a habilitação do município à condição de gestão semiplena.

35 Entre as pendências destacavam-se: proposição de forma de gerenciamento das unidades com vistas à municipalização; definição de políticas de recursos humanos; definição de custeio e investimento das unidades a serem municipalizadas; doctimento que comprovasse a criação do Fundo Municipal de Saúde, incluindo extrato bancário; comprovação da utilização de recursos e contrapartida; termo de compromisso aprovado pelo Conselho Municipal de Saúde (CMS) com metas a serem cumpridas; documento de compro- 
vação de criação do CMS; ata do CMS que aprovou o pleito de habilitação; ata da última reunião do CMS; portaria de nomeação dos médicos autorizadores de AIH e declaração de próprio punho declarando não ter vínculo com entidades, contrato e convênio com o SUS.

36 O processo de discussão das prioridades de investimento para o estado foi um processo longo, envolvendo a participação do representante do MS, do estado e de diversos municípios e, inicialmente, não estava diretamente relacionado aos recursos de investimento do REFORSUS.

37 As habilitações dos municípios na condição de gestão plena da atenção básica foram publicadas nas deliberaçōes da CIB/RJ no 07/97, 08/97 e 10/97. Os municípios recémemancipados, enquadrados na nova condição de gestão foram Seropédica, Macuco, Iguaba Grande e Pinheiral.

38 Estes secretários não necessariamente eram oriundos de municípios recém-emancipados ou das Prefeituras recém-eleitas. Muitos deles já exerciam a função de Secretário desde o início de 1996.

39. No estado do Rio formaram-se dez municípios novos em 1996, ampliando o número de 81 para 91 municípios.

40) Outros assuntos de importância foram discutidos na CIB/RJ no período: Modelo de cooperativas hospitalares; avaliação e julgamento dos pleitos de habilitação dos municípios às condiçōes de gestão da NOB SUS 01/93; NOB SUS 01/96; Canal Saúde/Fiocruz; revisão dos tetos financeiros municipais no âmbito ambulatorial; Plano Nacional de Combate ao Dengue.

41 O sistema APAC foi implantado no estado a partir de determinação da NOB SUS 01/ 96 como um instrumento de pagamento diferenciado para procedimentos de alta complexidade, com a finalidade de cadastrar e identificar os pacientes renais crônicos do estado em uso de terapia renal substitutiva.

12 Apesar da FRI não ter sido efetivamente implementada para o estado do RJ como um todo, os recursos destinados à Nova Iguaçu pelos municípios da Baixada Fluminense foram alocados no teto financeiro deste município no final de 1997. No entanto, como no restante do estado permanecia a metodologia para o cálculo financeiro do teto ambulatorial aprovada em agosto de 1995 (a metodologia do "migração automática"), os recursos alocados no teto de Nova Iguaçu não foram provenientes dos municípios da Baixada, mas sim, "retirados" dos minicípios do estado como um todo.

$43 \mathrm{Na}$ época, além do quadro de funcionários próprios da SES/RJ, atuavam no CPS/SPD duas consultoras contratadas pela SES/RJ, que ficaram envolvidas basicamente nas atividades da Comissão PPI.

44 As alterações dos tetos nos estados ocorreram no ano de $1998 \mathrm{em}$ dois momentos distintos: em março, em decorrência da publicação e dos ajustes financeiros referentes ao $\mathrm{PAB}$ e em junho, em decorrência dos $25 \%$ de ajuste em todos os valores da tabela de procedimentos do SIH-SUS e SIH-SUS.

45 Os recursos do CAPD, que até então eram de responsabilidade do estado, são repassados para os tetos dos municípios.

46 Em janeiro de 1999, assumiu a Secretaria de Estado de Saúde o Dr. Gilson Cantarino 
A Comissão Intergestores Bipartite - a CIB do Rio de Janeiro

O’Dwyer, Secretário Municipal de Saúde de Niterói e presidente do CONASEMS. Sua indicação recebeu o apoio do COSEMS/RJ e significou grande expectativa de mudanças na relação estado-municípios por parte dos secretários municipais de saúde.

O Programa HELP consistiu na contratação, a partir de processo licitatório - concorrência pública na modalidade "técnica e preço" - de empresas privadas para prestar serviços de administração dos seis hospitais estaduais existentes (Machado, 1999).

$\mathrm{Na}$ proposta o estado estipula o controle das Fichas de Programação Orçamentárias (FPO) dos serviços ambulatoriais de média e alta complexidade, estabelecendo que estas nāo poderiam ser modificadas sem a anuência do estado e aprovação da CIB/RJ. Além disso, propõe a instituição de um instrumento de autorização dos procedimentos de alto custo/alta complexidade em todo o estado, sendo que a operacionalizaçāo das referências se daria através de uma Central de Referência para Procedimentos de Alto Custo/Alta Complexidade, gerida pela SES/RJ, município do RJ e Gerência Estadual do MS no RJ (GEREST/RJ).

4y Outros assuntos de destaque foram discutidos no período: Avaliação e julgamento dos pleitos de habilitação dos municípios às condições de gestão da NOB SUS 01/96; Credenciamento e cadastramento de unidades; Emendas parlamentares; Modelo do relatório de gestão a ser utilizados nos municípios; Plano Nacional de Combate ao Dengue; Campanha contra o sarampo; REFORSUS; Municipalização da vigilância e fiscalização sanitária; Malária; Regimento Interno da CIB/RJ; Intervenção em Nova Friburgo; Descentralização das ações de controle, avaliação e auditoria; Descentralização dos hospitais federais; Definição do PAB; Programa de Saúde da Família (PSF) e Programa de Agentes Comunitários de Saúde (PACS); Plano de Combate às Carências Nutricionais; Sistema estadual de emergência; Sistema de atençāo à gestante de alto risco; Câmara de compensação interestadual de AIH; VIGISUS.

50 Todos os sete municípios habilitados em condição de gestāo semiplena na NOB SUS 01/ 93 passaram a ser gestores plenos na NOB SUS 01/96.

51 O trabalho de Oliveira (1998) mostra que o CMS de Nova Friburgo atuou também de forma decisiva junto à $C I B / R J$ durante o processo de habilitaçāo do município à condição semiplena da NOB SUS 01/93, exigindo o cumprimento dos requisitos de previstos na norma.

52 A discussão sobre os consórcios intermunicipais de saúde aparece na CIB/RJ muito tangencialmente. No Plano Orçamentário do Estado para 1998 foi aprovado um total de R\$ 20 milhōes de recursos próprios do estado para serem investidos em planos de consórcios. Enquanto uma diretriz estadual e uma política de investimento de recursos próprios do estado, o único Plano aprovado em 1998 (Plano da Região Noroeste), com valor inferior a $R \$ 2$ milhões a ser transferido gradativamente segundo cronograma específico, aparece na pauta da CIB/RJ como informe e não como ponto para discussão.

53 Em 1995, municipalização de PAMs e de Maternidades Federais no Rio representou transferência de recursos federais para o município. A negociação se deu diretamente entre o nível federal e o município, sem a $\mathrm{CIB} / \mathrm{RJ}$. 


\section{Referências Bibliográficas}

ABRUCIO, Fernando Luiz. Os Barões da Federação: os governadores e a redemocratização brasileira. São Paulo: HUCITEC, 1998.

AZEM, Eliana Pereira; SANTOS, Maria Manuela P.C.A.; MOYSÉS, Neuza Maria Nogueira. O SUDS/RJ e a municipalização: um processo em andamento. RAP, v. 25, n. 2, p. 4-30, 1991.

BRASIL. Ministério da Saúde. Secretaria de Assistência à Saúde. Manual de operação: reforço à reorganização do SUS. Brasília: Ministério da Saúde, 1996.

CONSELHO DOS SECRETÁRIOS MUNICIPAIS DE SAÚDE DO ESTADO DO RIO DE JANEIRO. Manual do gestor. Rio de Janeiro: COSEMS/RJ, 1997.

LABRA, Maria Eliana. Análise de políticas, modos de policy-making $e$ intermediação de interesses: uma revisão. [S. 1. : s. n.], 1999. Mimeografado.

LEVCOVITZ, Eduardo; YAMAMOTO, Edison K., SILVEIRA, Telma Ruth Pereira. Praticando a descentralização: desenvolvimento gerencial e institucional na SES-RJ- 1988/1989. Revista Saúde em Debate. Londrina: CEBES, n. 29, p. 30-36, 1990.

LIMA, Luciana Dias. O processo de implementação de novas estruturas gestoras no Sistema Único de Saúde: um estudo das relações intergovernamentais na CIB do RJ. 1999. Dissertação (Mestrado em Saúde Coletiva) - Instituto de Medicina Social, Universidade do Estado do Rio de Janeiro, Rio de Janeiro.

MACHADO, Cristiani Vieira. Contexto, atores, instituiçōes: um estudo exploratório acerca das modalidades de gerência nos hospitais públicos do Município do Rio de Janeiro nos anos 90. 1999. Dissertação (Mestrado em Saúde Coletiva) - Instituto de Medicina Social, Universidade do Estado do Rio de Janeiro, Rio de Janeiro.

BRASIL. Ministério da Saúde. Secretaria de Assistência à Saúde. Relatório dos encontros macroregionais da Secretaria de Assistência à Saúde do Ministério da Saúde com as comissões intergestores bipartites. Brasília:SAS/MS, 1995 a. Mimeografado. 
BRASIL. Ministério da Saúde. Secretaria de Assistência à Saúde. Segundo relatório sobre o processo de organização da gestão da assistência à saúde. Brasília:SAS/MS, 1995 b. Mimeografado.

BRASIL. Ministério da Saúde. Secretaria de Assistência à Saúde. Terceiro relatório sobre o processo de organizaçāo da gestāo da assistência à saúde: a programação hospitalar integrada - 1995. Brasília:SAS/MS, 1995 c. Mimeografado.

OLIVEIRA, Gilson Saippa. O desenho institucional do SUS e a definição da agenda local: um estudo de caso no Município de Nova Friburgo. 1998. Dissertação (Mestrado em Saúde Pública) - Escola Nacional de Saúde Pública, Rio de Janeiro.

PARADA, Roberto. Sistema Estadual de Saúde, descentralização e relações intergovernamentais: um estudo sobre o Estado do Rio de Janeiro. 1997. Dissertação (Mestrado em Saúde Coletiva) - Instituto de Medicina Social, Universidade do Estado do Rio de Janeiro, Rio de Janeiro.

REVISTA DIVULGAÇÃO EM SAÚDE PARA DEBATES. Londrina: CEBES, set. 1989.

RIO DE JANEIRO (Estado). Secretaria de Estado de Saúde. Rio Saúde: relatório de gestão da SES/RJ, 1987-1989. Rio de Janeiro: SES/ RJ, 1990. 


\section{ABSTRACT}

\section{The Comissões Intergestores Bipartite (CIB) in Rio de Janeiro}

This paper investigates the structure of the Comissões Intergestores Bipartite - CIB (commissions formed by managers from the municipal and state. administrations), as new decision centers in health politics. Analyzing a concrete case - the CIB of Rio de Janeiro State - one tried to ponder on how internal variables in health politics can contribute to the formation of the federative pact in health, as well as to the implementation of SUS's health system model. The study showed that the CIBs played an essential role in the development of national directives and in the decentralization of the health system. It has been observed that the accomplishment of politics, through collegiate management instances, leads to the establishment of a partnership between state and municipalities, and to the consolidation of a negotiation practice between the politics' local managers - more balanced, democratic and participant. Nevertheless, the study carried out in Rio de Janeiro suggests that the CIBs still must incentive the discussion and collective formulation in order to confront local-regional problems, aiming at structuring the intermunicipal and state health system.

Keywords: Comissão Intergestores Bipartite; health politics' decentralization; intergovernmental relations; health system.

Recebido em: janeiro de 2001.

Aprovado em: fevereiro de 2001. 